\title{
AN ANALYTICAL METHOD FOR THE OPTIMUM THERMAL DESIGN OF CONVECTIVE LONGITUDINAL FIN ARRAYS
}

\author{
ALESSANDRO FRANCO \\ Dipartimento di Energetica “L. Poggi” \\ Università di Pisa \\ Largo Lucio Lazzarino - 56126 PISA \\ Tel. 050-569632/35 fax 050-569604 \\ e-mail: alessandro.franco@ing.unipi.it
}

\begin{abstract}
The paper analyzes the problem of the optimum thermal design of free and forced convection fin arrays composed of longitudinal fins with constant thickness. Two different optimization problems have been considered: the minimization of the weight for a given heat flow and the maximization of the heat flow for a given fin-weight. Two different geometrical configurations of the fin array have been considered: closed array and open array. The procedure for the optimization is provided in a general case and a complete analytical solution of the problem, for the case with the tip approximated as being insulated, is developed. The paper contains several illustrative examples of the application of the proposed optimization procedure.
\end{abstract}

Keywords: Extended surfaces, Rectangular Plate-Fin array, Convection, Optimization, Fin spacing 


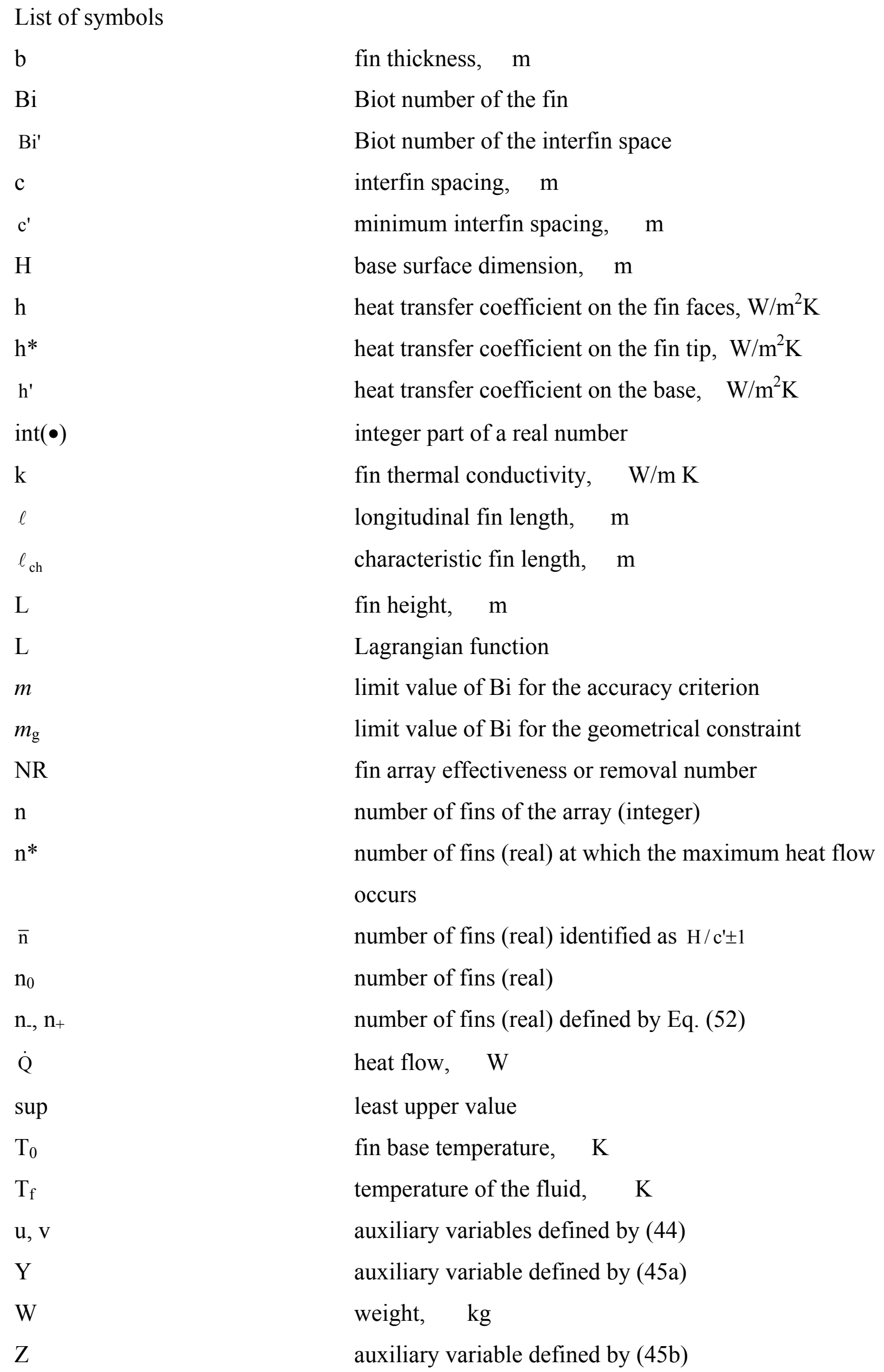

$\mathrm{n}$

$\mathrm{n}^{*}$

fin thickness, $\mathrm{m}$

Biot number of the fin

Biot number of the interfin space

interfin spacing, $\mathrm{m}$

minimum interfin spacing, $\mathrm{m}$

base surface dimension, $\mathrm{m}$

heat transfer coefficient on the fin faces, $\mathrm{W} / \mathrm{m}^{2} \mathrm{~K}$

heat transfer coefficient on the fin tip, $\mathrm{W} / \mathrm{m}^{2} \mathrm{~K}$

heat transfer coefficient on the base, $\mathrm{W} / \mathrm{m}^{2} \mathrm{~K}$

integer part of a real number

fin thermal conductivity, $\mathrm{W} / \mathrm{m} \mathrm{K}$

longitudinal fin length, $\mathrm{m}$

characteristic fin length, $m$

fin height, $\mathrm{m}$

Lagrangian function

limit value of $\mathrm{Bi}$ for the accuracy criterion

limit value of $\mathrm{Bi}$ for the geometrical constraint

fin array effectiveness or removal number

number of fins of the array (integer)

number of fins (real) at which the maximum heat flow

occurs

number of fins (real) identified as $\mathrm{H} / \mathrm{c}^{\prime} \pm 1$

number of fins (real)

number of fins (real) defined by Eq. (52)

heat flow, W

least upper value

fin base temperature, $\mathrm{K}$

temperature of the fluid, $\mathrm{K}$

auxiliary variables defined by (44)

auxiliary variable defined by (45a)

weight, $\mathrm{kg}$

auxiliary variable defined by (45b) 
Greek symbols

$\beta$

$\Delta \mathrm{T}_{0 \mathrm{f}}$

$\varepsilon_{\mathrm{sf}}$

$\lambda$

$\rho$

$\gamma$

$\chi$

$\mathrm{X}$

$\varphi$

$\Phi$

$\psi$

$\Psi$

$\omega, \omega^{\prime}$

$\hat{\omega}$

\section{Subscripts}

F

g

$\mathrm{m}$

$\max$

opt

S

0 auxiliary variable for the optimization method

temperature difference defined as $\left(\mathrm{T}_{0}-\mathrm{T}_{\mathrm{f}}\right)$

effectiveness (removal number) of a single fin

Lagrange multiplier

shape factor of the longitudinal fin

specific weight of the fin material, $\mathrm{kg} / \mathrm{m}^{3}$

dimensionless heat flow of the fin

dimensionless heat flow of the array

heat flow enhancement factor of the single fin

heat flow enhancement factor of the array

dimensionless weight of the fin

dimensionless weight of the array

boundary ratios defined by Eqs. (3)

generic boundary ratio

relative to the single fin

relative to the geometrical constraint

relative to the accuracy criterion

maximum value

optimum value

relative to the plain surface

relative to a particular value 


\section{Introduction}

In the industrial practice, arrays of longitudinal rectangular profile fins are largely used to improve both the reliability and performance of electronic, telecommunications and power conversion systems and they find a specific application in the heat sinks for electronic cooling. The increase in the power density of electronic components currently under development and newer applications in the automotive industry and air cooled fuel cells require significant improvement in performance and are reshaping the way we design and manufacture heat sinks and finned arrays. This require a reexamination of the materials and methods used to manufacture fin arrays and optimization criteria. The optimization of extended surfaces is a classical heat conduction problem [1-3] but there are a lot of aspects requiring to be investigated and clarified mainly for what concerns the optimization of free and forced convection fin arrays. The analysis of recent literature shows that the argument is still object of discussion [4-5].
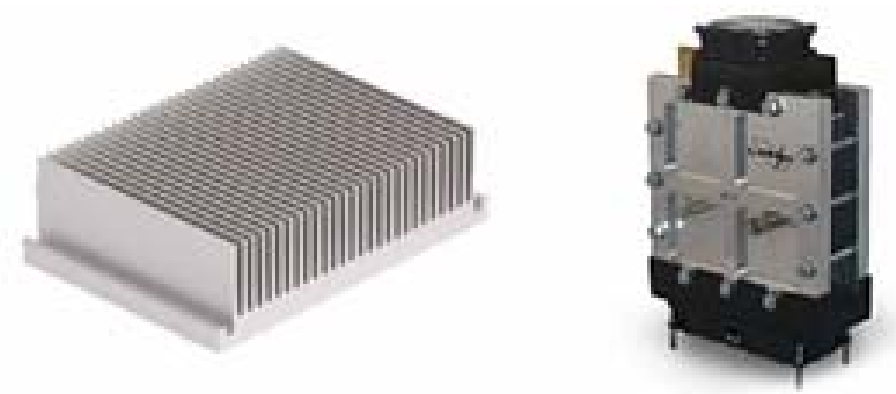

Figure 1. Fin arrays for cooling of electronic equipments and fuel cells

The longitudinal rectangular fin arrays made possible an analytical approach to the optimum design, that can furnish suggestions also for more complex extended surface configurations. It is possible to formulate several optimum design problems of fin arrays in convective heat transfer. In particular for arrays of longitudinal rectangular fins with constant thickness, there are mainly two approaches to perform a thermal optimization:

1) minimization of the weight for a given heat flow (dissipation), or maximization of the heat flow for a given weight, the dimensions of the optimum fin array are obtained assuming it composed by individually optimized fins;

2) considering simultaneously the fins and the unfinned area on the array base, a particular objective function to be minimised (maximised) can be defined (e.g. the weight of the fin 
array, the thermal resistance, the pressure drop etc.) obtaining, as result of the optimization process, the design of the fin array in term of number of fins, fin dimensions and interfin space.

The approach no. 1 gives origin to a design method, usually iterative and, if based on the optimum individual fin with adiabatic tip, quite simple and diffused in the practice. Extensive literature exists on this optimization problem [1]. About the second approach, the literature is less rich and where investigators consider it, in order to obtain analytical solutions, frequently they introduce simplified assumptions that made difficult to have a common reference base for the solution of the problem. The approach, referred in some meaningful papers [1, 6-10], can be quite complex but it seems to be idoneous to define solutions more convenient, especially in the application to advanced thermal control systems as in the case of electronic equipment [8].

Considering the problem of the thermal optimization of the fin array, the role, that the fluiddynamic conditions on the surface has in the optimization, appears evident. The convective heat transfer coefficient depends on the dimensions of the interfin spacing, both in natural and in forced convection. A variation both of the interfin spacing and of the fin height can involve a variation of the heat transfer coefficient and ane optimization procedure would require modeling the heat transfer coefficient variation as a function of the interfin spacing. This makes difficult to obtain an analytical solution of the problem without simplifications. According to the approach no. 2, i.e. considering simultaneously the fins and the primary surface of the array, the purpose of this paper is to revise the problem of the optimum thermal design of convectively cooled arrays of longitudinal rectangular fins and to suggest a new point of view for the solution of the problem. The optimum design of the fin arrays is considered as a classical multivariable optimization problem with inequality constraints and the optimum solution is found by minimizing the an objective function obtained by means of the analysis of the thermal problem, while other possible objective functions are transformed in constraints of the problem. In the case proposed, the fluid-dynamic problem has been bypassed imposing a minimum value of the interfin spacing, so that a well defined heat transfer coefficient on the fin faces can be maintained, varying the cross stream velocity by means of a fan.

Therefore the minimum interfin spacing is considered as a preassigned parameter, like the heat transfer coefficients on the tip, on the fin faces and on the base surface. The fin thickness, the fin height, the interfin spacing and the number of fins of the array are the independent 
optimization variables. In this way the problem can be solved analytically by a classical optimization technique: the generalized method of Lagrange multipliers.

\section{Model of the fin array}

The present analysis is limited to an array of rectangular longitudinal fins with constant thickness attached to a base plate surface, the primary surface. It is based on the Murray and Gardner assumptions provided in [11] with the exception of the insulated tip. Therefore there are two different heat transfer coefficients, $h$ on the fin faces and $h^{*}$ on the fin tip, both assumed uniform and constant.

The author have already developed a method for the optimum design of the single longitudinal fin based on the aforesaid model [12]; this method can be used also for the design of a fin arrays according to the approach no. 1 of the introduction, while the method proposed in the present paper can be directly related to the approach no. 2 .

For the fin array the conductive model is the same of the single fin, assuming a further hypothesis: the unfinned area of the array base is isothermal, with the same temperature of the base of the fin, and the heat transfer coefficient h' is uniform and constant. It has been already mentioned that, to consider constant the heat transfer coefficient on the fin faces and on the basic surface is an approximation. Actually, these coefficients depend on the velocity field in the gaps between the fins of the array. Three convective heat transfer coefficients $h, h^{*}$ and $h^{\prime}$ are considered, assuming that they maintain a preassigned value if the interfin spacing is greater than a limit value $c^{\prime}$. The idea that finned surface is subjected to uniform surface heat transfer coefficient is well accepted in the literature as discussed also in recent works on the same argument $[4,10]$.

Under this hypothesis there is the idea that, for a given longitudinal development of the array, in case of low variations of the dimensions of the fin channels, the mean values of the heat transfer coefficients, mainly in forced convection, can be maintained equal to the previously fixed values with an opportune variation of the fluid flow velocity; this variation is of limited value if the interfin spacing is maintained over $5 \mathrm{~mm}$. [10].

Fig. 2 shows the cross sectional view of the fin array. The configurations considered are two: the first, "open array", is represented in Fig. 2a, the second, "closed array" in Fig. 2b. 


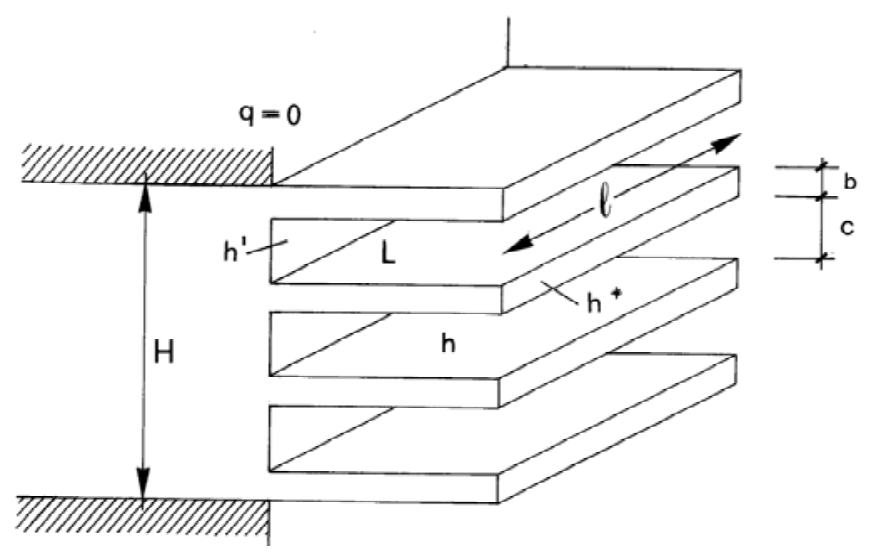

a) open array

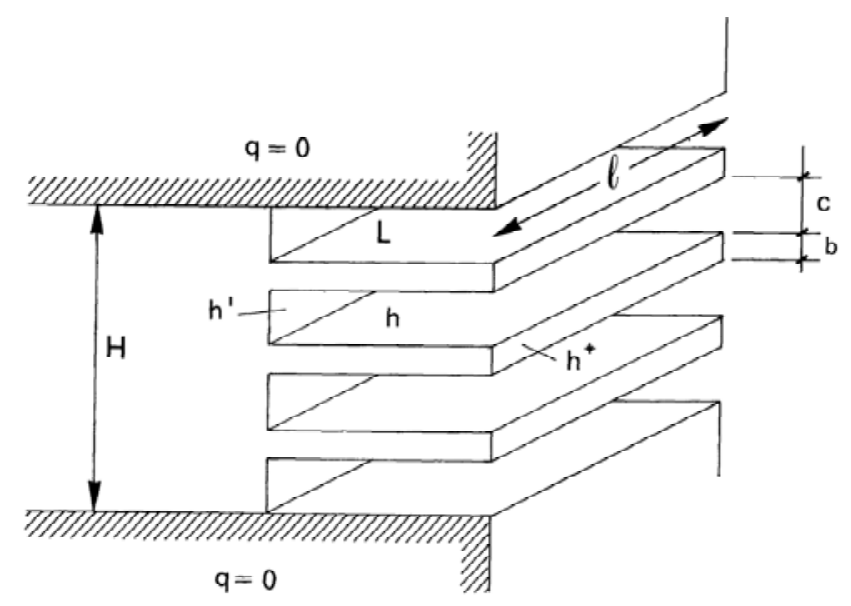

b) closed array

Figure 2. Schematic representation of the fin array configurations

In the first case the number of fins is higher than the interfin spaces, while in the second case there is one interfin space more than the fins. From the "characteristic length of the fin", defined as ratio between the thermal conductivity of the fin material and the heat transfer coefficient on the fin faces:

$$
\ell_{\mathrm{ch}}=\mathrm{k} / \mathrm{h}
$$

some dimensionless variables, useful to the array modelization, can be introduced (Table 1). 
Table 1. Typical characteristic length

\begin{tabular}{|l|c|c|}
\hline \multicolumn{1}{|c|}{ Material } & Cooling fluid & $\boldsymbol{k} / \mathbf{h}(\mathbf{m})$ \\
\hline Stainless steel & Water, high Re & 0.002 \\
\hline Polymer & Air, forced convection & 0.01 \\
\hline Copper & Water, high Re & 0.0475 \\
\hline Aluminum & Water, low Re & 0.160 \\
\hline Aluminum & Air, forced convection & 1.333 \\
\hline Carbon steel & Air, natural convection & 4.7 \\
\hline
\end{tabular}

Among these variables, those related to the array geometry are the following:

$$
\mathrm{Bi}=\frac{\mathrm{b}}{2 \ell_{\mathrm{ch}}}=\frac{\mathrm{hb}}{2 \mathrm{k}} ; \quad \mathrm{Bi}^{\prime}=\frac{\mathrm{c}^{\prime}}{2 \ell_{\mathrm{ch}}}=\frac{\mathrm{hc}^{\prime}}{2 \mathrm{k}} ; \quad \rho=\frac{2 \mathrm{~L}}{\mathrm{~b}}
$$

while the variables related to the convective boundary conditions are respectively:

$$
\omega=\mathrm{h}^{*} / \mathrm{h} ; \quad \omega^{\prime}=\mathrm{h}^{\prime} / \mathrm{h}
$$

The weight of an array composed by a total number of fins $\mathrm{n}$ and the total heat flow dissipated -assumed positive for the case of cooled fin $\left(T_{0}>T_{f}\right)$ - are given by

$$
\left\{\begin{array}{l}
\mathrm{W}=\mathrm{nW}_{\mathrm{F}} \\
\dot{\mathrm{Q}}=\mathrm{n} \dot{\mathrm{Q}}_{\mathrm{F}}+(\mathrm{n} \pm 1) \dot{\mathrm{Q}}_{\mathrm{S}}
\end{array}\right.
$$

The sign inside the brackets in the second equation of the system (4) must be assumed positive for the "closed" array and negative for the "open" array. $\mathrm{W}_{\mathrm{F}}$ and $\dot{\mathrm{Q}}_{\mathrm{F}}$ are the weight and the heat flow of the single fin, while $\dot{Q}_{S}$ is the heat flow dissipated from the unfinned area on the array base, given by

$$
\dot{\mathrm{Q}}_{\mathrm{S}}=\mathrm{h}^{\prime} \mathrm{c} \cdot \ell \cdot\left(\mathrm{T}_{0}-\mathrm{T}_{\mathrm{f}}\right)=\mathrm{h}^{\prime} \mathrm{c} \cdot \ell \cdot \Delta \mathrm{T}_{0 \mathrm{f}}
$$

The weight and the heat flow of the fin array can be given in dimensionless form as:

$$
\left\{\begin{array}{l}
\Psi=\frac{\mathrm{W}}{\gamma \ell \ell_{\mathrm{ch}}^{2}} \\
\mathrm{X}=\frac{\dot{\mathrm{Q}}}{\mathrm{k} \ell \cdot \Delta \mathrm{T}_{0 \mathrm{f}}}
\end{array}\right.
$$

The weight of the single fin, and the dimensionless heat flow obtained by the 1-D model can be also expressed in dimensionless form as:

$$
\psi=\frac{\Psi}{\mathrm{n}}=\frac{\mathrm{W}_{\mathrm{F}}}{\gamma \ell \ell_{\mathrm{ch}}^{2}}=2 \rho \mathrm{Bi}^{2}
$$




$$
\chi=\frac{\dot{\mathrm{Q}}_{\mathrm{F}}}{\mathrm{k} \ell \cdot \Delta \mathrm{T}_{0 \mathrm{f}}}=2 \cdot \sqrt{\mathrm{Bi}} \frac{\operatorname{th}(\rho \sqrt{\mathrm{Bi}})+\omega \sqrt{\mathrm{Bi}}}{1+\omega \sqrt{\mathrm{Bi}} \cdot \operatorname{th}(\rho \sqrt{\mathrm{Bi}})}
$$

As a characteristic case the term $\chi$ for the infinitely long fin $(\rho \rightarrow \infty)$, approaches to the well known asymptotic value (Fig. 3)

$$
\chi_{\max }=2 \cdot \sqrt{\mathrm{Bi}}
$$

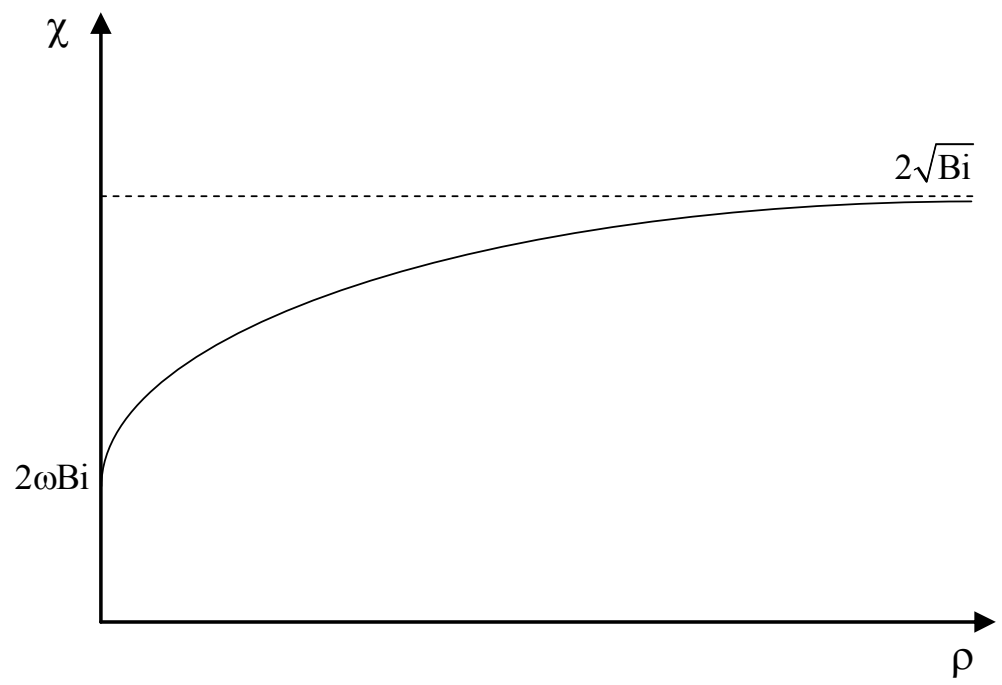

Figure 3. Dimensionless heat flow trend for a given value of the Biot number for a defined value of $\omega$.

As indicative parameter of the fin array performance, the difference between the total heat flow exchanged by the array and the heat flow exchanged by the bare surface (basic surface without fins) operating under the same boundary conditions can be introduced in dimensionless form as:

$$
\Phi=\frac{\dot{\mathrm{Q}}-\mathrm{h}^{\prime} \ell \mathrm{H} \cdot \Delta \mathrm{T}_{0 \mathrm{f}}}{\mathrm{k} \ell \cdot \Delta \mathrm{T}_{0 \mathrm{f}}}
$$

referred from here as "heat transfer enhancement factor" of the fin array. The parameter $\Phi$ can be expressed as a function of some of the previously defined dimensionless quantities

$$
\Phi=\mathrm{X}-2 \omega^{\prime} \mathrm{Bi}^{\prime}\left(\mathrm{H} / \mathrm{c}^{\prime}\right)
$$

The "heat transfer enhancement factor" relative to the single fin is

$$
\varphi=\Phi / \mathrm{n}
$$

that can be also expressed in the form

$$
\varphi=\chi-2 \omega^{\prime} \mathrm{Bi}
$$




\section{Optimum design problem: main elements}

The optimum design problem requires the definition of an objective function, of the thermal and fluiddynamic model of the fin array, of the constraints and of the true variables of the problem. The objective is to minimize the weight of the fin array for a given heat flow or to maximize the heat flow for a given weight of the array. The conductive model of the fin array contains a lot of quantities that must be considered as preassigned parameters: the geometrical dimensions $\mathrm{H}, \ell, \mathrm{c}^{\prime}$, the physical properties of the materials $\gamma$ and $\mathrm{k}$, the convective heat transfer coefficients $h, h^{*}$ and $h^{\prime}$, and the temperatures of the primary surface $T_{0}$ and of the fluid $\mathrm{T}_{\mathrm{f}}$.

The true design variables for the problem are the number $n$ of fins of the array, the fin thickness $\mathrm{b}$ and the fin heigth $\mathrm{L}$. The objective functions are the weight $\mathrm{W}$, if the heat flow $\dot{Q}$ is assigned, or the heat flow if the weight is given. The optimum design problem is a typical constrained optimization problem. Further constraints, that will be discussed in the next paragraphs, have to be joined to the equality constraint given by assigning the heat flow or the weight.

\subsection{Constraint on the maximum number of fins}

When the geometrical dimensions of the base surface are given, the number of fins of the array is an integer value with a minimum equaling 1 for the closed array or 2 for the open array and a maximum consistent with the minimum permissible interfin space, $c^{\prime}$. Really, the maximum number of fins of the array has to be lower than the real number $\bar{n}$

$$
\overline{\mathrm{n}}=\left(\frac{\mathrm{H}}{\mathrm{c}^{\prime}} \pm 1\right)
$$

with positive sign for the "open array" and negative for the "closed array", so that yields

$$
\mathrm{n}_{\text {nax }}=\operatorname{int}\left(\mathrm{H} / \mathrm{c}^{\prime}\right) \pm 1 \leq \overline{\mathrm{n}}
$$

\subsection{Constraint defined by the convenience criterion of the fin array}

In the literature the "fin convenience criterion" means the condition for which the finned surface has advantages over the primary surface, considered by thermal or economical point of view. As regards to the thermal point of view, there are different ways to establish that condition: resorting to fin effectiveness $[1,13]$, or removal number $[3,14]$ is usually 
suggested. In this work the heat transfer enhancement factor (augmentation factor) of the fin array, $\Phi$, defined by Eqs. (10) and (11) is preferred. In particular, it is proposed that the evaluation of the thermal convenience be based both on the condition of positive fin array enhancement factor and also on the analysis of its first derivative with respect to the fin height; according to the idea that the fin has advantages over the primary surface as long as the heat flow increases with the increase of the fin height $[13,15]$.

Taking into account the definition of the fin array enhancement factors defined by Eqs. (10)(13), it is easy to show that the thermal convenience criterion, if the 1-D model holds, involves only the single fin enhancement factor; requiring that:

$$
\varphi=\chi-2 \omega^{\prime} \mathrm{Bi}>0 \quad \text { and } \quad \frac{\partial \varphi}{\partial \rho}>0
$$

Imposing the condition on the derivative, i.e. that $\chi$ be an increasing function of $\rho$, it results that, as shown in [12]:

$$
1-\omega^{2} \cdot \mathrm{Bi} \geq 0
$$

on the other hand, it is not difficult to demonstrate that

$$
\varphi \geq 0 \Rightarrow \quad \begin{aligned}
& \text { if } \quad \omega \geq \omega^{\prime} \Rightarrow \mathrm{Bi} \leq 1 /\left(\omega \cdot \omega^{\prime}\right) \\
& \text { if } \quad \omega<\omega^{\prime} \Rightarrow \mathrm{Bi} \leq 1 /\left(\omega^{\prime 2}\right)
\end{aligned}
$$

Therefore, joining the conditions defined by Eqs. (16) and (17), the thermal convenience criterion, can be summarized as follows

$$
\mathrm{Bi} \leq \frac{1}{\hat{\omega}^{2}}
$$

with

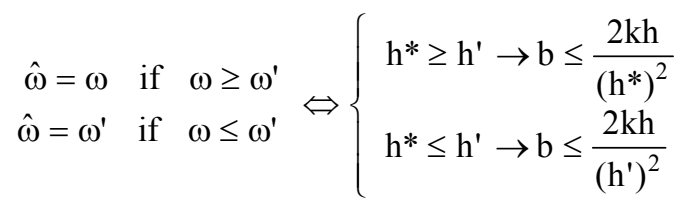

It must be remarked that, assuming equal the heat transfer coefficients $h, h^{*}$ and $h^{\prime}$ at the fin faces, at the fin tip and at the primary surface in the gap between the fins, respectively, no difference occurs between the usual condition that the effectiveness be greater than one, or that the criterion defined by Eq. (18a) be satisfied. Moreover, in case of validity of the 1-D model, the aforesaid criterion (18) is completely consistent with each physically meaningful 
situation $\omega \neq \omega^{\prime} \neq 1 \Leftrightarrow h^{*} \neq h^{\prime} \neq h$ and, in particular, with $\omega=0$, i.e. for fins with adiabatic tip.

\subsection{Constraint defined by the accuracy of the 1-D conduction approximation}

About the application of the 1-D model, for a longitudinal fin with constant thickness it is correct for Biot numbers much less than unity, $\mathrm{Bi}<<1$ [3]. A more specific condition results from the "accuracy criterion" [12], based on the evaluation of the accuracy of the results obtained with the 1-D fin heat conduction model [16-18]. As accuracy criterion the following inequality can be assumed:

$$
\mathrm{Bi} \leq m \quad \Leftrightarrow \quad \mathrm{b} \leq 2 \mathrm{~km} / \mathrm{h}
$$

As example, the accuracy is within the $1 \%$ if $\mathrm{Bi}<0.04$ [12]. So the Biot number, i.e. the fin thickness, is bounded both by the limit values defined by the aforesaid fin thermal convenience criterion and by the accuracy criterion. Obviously, it is necessary that the two conditions be both satisfied. It is not difficult to check that, for the longitudinal fin array, in many engineering situations the accuracy criterion is more restrictive than the convenience criterion.

\subsection{Constraint defined by the geometry}

For each array composed by a number $\mathrm{n}$ of rectangular plate fins, it is possible to determine the maximum fin thickness compatible with the constraint of the minimum interfin spacing between two contiguous fins. If $b$ is the fin thickness and $n$ the number of fins, it is necessary that

$$
\mathrm{c}=\frac{\mathrm{H}-\mathrm{nb}}{\mathrm{n} \pm 1} \geq \mathrm{c}^{\prime}
$$

so that it results that the maximum permissible thickness is

$$
\mathrm{b}_{\max }=\frac{\mathrm{H}-(\mathrm{n} \pm 1) \cdot \mathrm{c}^{\prime}}{\mathrm{n}}
$$

where the positive (negative) sign is valid in the case of closed (open) array. In both the cases, the satisfaction of the constraint on the interfin spacing can be turned in dimensionless term in a limitation of the Biot number. So that it yields 


$$
\mathrm{Bi} \leq m_{\mathrm{g}}=\mathrm{Bi}^{\prime} \frac{\overline{\mathrm{n}}-\mathrm{n}}{\mathrm{n}}
$$

that furnishes a bound similar to the one given by the convenience criterion and by the accuracy criterion, discussed in the previous sections.

\subsection{Maximum heat flow of the fin array consistent with the 1-D model}

An important element of the fin array design is the knowledge of the upper limit heat flow that can be dissipated with reference to a required heat exchange surface dimension. The maximum value of the heat flow, consistent with the one-dimensional model of the fin array, can be obtained by analyzing the array heat transfer enhancement $\Phi$ as function of the number of fins $n$, considered as a real continuous variable. Introducing in the Eq. (9) the Biot numbers defined by the accuracy constraint, $m$, or by the geometrical constraint, $m_{\mathrm{g}}$, the array heat transfer enhancement is bounded as follows

$$
\begin{array}{cc}
\Phi \leq \Phi_{\mathrm{m}}(\mathrm{n})=\mathrm{n} \cdot\left[2 \sqrt{m}-2 \omega^{\prime} m\right] & \text { for } 1 \leq \mathrm{n} \leq \mathrm{n}_{0} \\
\Phi \leq \Phi_{\mathrm{g}}(\mathrm{n})=2\left[\sqrt{\mathrm{Bi} \cdot \mathrm{n}(\overline{\mathrm{n}}-\mathrm{n})}-\omega^{\prime} \mathrm{Bi}^{\prime}(\overline{\mathrm{n}}-\mathrm{n})\right] & \text { for } \mathrm{n}_{0} \leq \mathrm{n} \leq \overline{\mathrm{n}}
\end{array}
$$

where the bounding quantities are coincident at $\mathrm{n}=\mathrm{n}_{0}$. Because $\Phi_{\mathrm{m}}(\mathrm{n})$ increases with $\mathrm{n}$, in the range where the accuracy constraint is more restrictive than the geometrical one it results

$$
\sup \left[\Phi_{\mathrm{m}}(\mathrm{n})\right]=\Phi_{\mathrm{m}}\left(\mathrm{n}_{0}\right)=\mathrm{n}_{0} \cdot\left[2 \sqrt{m}-2 \omega^{\prime} m\right] \quad \text { for } \mathrm{n} \leq \mathrm{n}_{0}
$$

On the contrary, the function $\Phi_{\mathrm{g}}(\mathrm{n})$ shows a maximum value; the condition $\partial \Phi_{\mathrm{g}} / \partial \mathrm{n}=0$ gives that it occurs at

$$
\mathrm{n}^{*}=\frac{1}{2} \overline{\mathrm{n}} \cdot\left[1+\sqrt{\frac{\omega^{\prime 2} \mathrm{Bi}^{\prime}}{1+\omega^{\prime 2} \mathrm{Bi}^{\prime}}}\right]
$$

so that

$$
\left\{\begin{array}{llll}
\text { if } & \mathrm{n}_{0}<\mathrm{n}^{*} \Rightarrow \sup \left[\Phi_{\mathrm{g}}(\mathrm{n})\right]=\Phi_{\mathrm{g}}(\mathrm{n} *) & \text { for } & \mathrm{n}^{*} \leq \mathrm{n}<\overline{\mathrm{n}} \\
\text { if } & \mathrm{n}_{0} \geq \mathrm{n}^{*} \Rightarrow \sup \left[\Phi_{\mathrm{g}}(\mathrm{n})\right]=\Phi_{\mathrm{g}}\left(\mathrm{n}_{0}\right) & \text { for } & \mathrm{n}_{0} \leq \mathrm{n}<\overline{\mathrm{n}}
\end{array}\right.
$$

By means of Eqs. (6) and (11) the aforesaid values can be turned to dimensional heat flow

$$
\dot{\mathrm{Q}}\left(\mathrm{n}^{*}\right)=\mathrm{k} \ell \Delta \mathrm{T}_{0 \mathrm{f}} \cdot\left\{\overline{\mathrm{n}} \cdot\left[\sqrt{\mathrm{Bi}^{\prime}\left(1+\omega^{\prime 2} \mathrm{Bi}^{\prime}\right)}+\omega^{\prime} \mathrm{Bi}^{\prime}\right] \mp 2 \omega^{\prime} \mathrm{Bi}^{\prime}\right\}
$$




$$
\dot{\mathrm{Q}}\left(\mathrm{n}_{0}\right)=\mathrm{k} \ell \Delta \mathrm{T}_{0 \mathrm{f}} \cdot\left\{2 \mathrm{n}_{0} \cdot\left[\sqrt{m}+\omega^{\prime} \mathrm{Bi}^{\prime}\right] \mp 2 \omega^{\prime} \mathrm{Bi}^{\prime}\right\}
$$

where the sign in upper position is for open array and in lower position for closed array. Really, taking into account that the fin number is an integer; and defining the integers

$$
\left\{\begin{array} { l } 
{ \hat { \mathrm { n } } _ { 0 } = \operatorname { i n t } ( \mathrm { n } _ { 0 } ) } \\
{ \widetilde { \mathrm { n } } _ { 0 } = \operatorname { i n t } ( \mathrm { n } _ { 0 } ) + 1 }
\end{array} \quad \left\{\begin{array}{l}
\hat{\mathrm{n}}^{*}=\operatorname{int}(\mathrm{n} *) \\
\widetilde{\mathrm{n}}^{*}=\operatorname{int}(\mathrm{n} *)+1
\end{array}\right.\right.
$$

then it results

$$
\begin{cases}\dot{\mathrm{Q}}_{\max }=\mathrm{k} \ell \Delta \mathrm{T}_{0 \mathrm{f}}\left\{\sup \left[\Phi_{\mathrm{g}}\left(\hat{\mathrm{n}}^{*}\right), \Phi_{\mathrm{g}}\left(\tilde{\mathrm{n}}^{*}\right)\right]+2 \omega^{\prime} \mathrm{Bi}^{\prime}\left(\frac{\mathrm{H}}{\mathrm{c}^{\prime}}\right)\right\} \leq \dot{\mathrm{Q}}\left(\mathrm{n}^{*}\right) & \text { for } \mathrm{n}_{0}<\hat{\mathrm{n}}^{*} \\ \dot{\mathrm{Q}}_{\max }=\mathrm{k} \ell \Delta \mathrm{T}_{0 \mathrm{f}}\left\{\sup \left[\Phi_{\mathrm{m}}\left(\hat{\mathrm{n}}^{*}\right), \Phi_{\mathrm{g}}\left(\tilde{\mathrm{n}}^{*}\right)\right]+2 \omega^{\prime} \mathrm{Bi}^{\prime}\left(\frac{\mathrm{H}}{\mathrm{c}^{\prime}}\right)\right\} \leq \dot{\mathrm{Q}}\left(\mathrm{n}^{*}\right) & \text { for } \hat{\mathrm{n}}^{*}<\mathrm{n}_{0}<\mathrm{n}^{*} \\ \dot{\mathrm{Q}}_{\max }=\mathrm{k} \ell \Delta \mathrm{T}_{0 \mathrm{f}}\left\{\sup \left[\Phi_{\mathrm{m}}\left(\hat{\mathrm{n}}_{0}\right), \Phi_{\mathrm{g}}\left(\tilde{\mathrm{n}}_{0}\right)\right]+2 \omega^{\prime} \mathrm{Bi}^{\prime}\left(\frac{\mathrm{H}}{\mathrm{c}^{\prime}}\right)\right\} \leq \dot{\mathrm{Q}}\left(\mathrm{n}_{0}\right) & \text { for } \mathrm{n}_{0} \geq \mathrm{n}^{*}\end{cases}
$$

However a sufficient estimation of $\dot{\mathrm{Q}}_{\max }$ can be given by

$$
\begin{array}{ll}
\dot{\mathrm{Q}}\left(\mathrm{n}^{*}\right) & \text { if } \mathrm{n}_{0}<\mathrm{n}^{*} \\
\dot{\mathrm{Q}}\left(\mathrm{n}_{0}\right) & \text { if } \mathrm{n}_{0} \geq \mathrm{n}^{*}
\end{array}
$$

furthermore after some algebraic calculations, it results that

$$
\mathrm{n}_{0}<\mathrm{n}^{*} \Leftrightarrow \mathrm{m}>\mathrm{Bi}^{\prime}\left[\sqrt{1+\omega^{\prime 2} \mathrm{Bi}^{\prime}}-\sqrt{\omega^{\prime 2} \mathrm{Bi}^{\prime}}\right]^{2}
$$

\subsection{Final remarks about the constraints}

Some useful considerations about the constraints and their implications can be remarked.

First, starting from the assumption that the convenience criterion be satisfied, it is important to determine the condition for which the geometrical constraint is more restrictive than the accuracy one, resulting:

$$
m_{\mathrm{g}} \leq m \quad \Leftrightarrow \quad \mathrm{n} \geq \mathrm{n}_{0}=\frac{\overline{\mathrm{n}}}{1+m / \mathrm{Bi}^{\prime}}
$$

Second, as consequence of the constraints, there is a limit to the array heat transfer enhancement factor, i.e. to the heat flow, consistent with the 1-D model of the fin array. 
The dimensionless heat flow of the 1-D fin has a maximum depending on the square root of the Biot number, as given by Eq. (9), while the Biot number is limited by the constraint too. Therefore it is possible to show that, for the validity of the 1-D model of the fin array, the heat flow is required to be lower than a maximum value, and such maximum bounded as follows

$$
\begin{gathered}
\text { for } \mathrm{n}_{0}<\mathrm{n}^{*} \rightarrow \quad \dot{\mathrm{Q}}_{\max } \leq \dot{\mathrm{Q}}\left(\mathrm{n}^{*}\right) \\
\dot{\mathrm{Q}}\left(\mathrm{n}^{*}\right)=\mathrm{k} \ell \cdot \Delta \mathrm{T}_{0 \mathrm{f}}\left\{\overline{\mathrm{n}} \cdot\left[\sqrt{\mathrm{Bi}^{\prime}\left(1+\omega^{\prime 2} \mathrm{Bi}^{\prime}\right)}+\omega^{\prime} \mathrm{Bi}^{\prime}\right] \mp 2 \omega^{\prime} \mathrm{Bi}^{\prime}\right\} \\
\text { for } \mathrm{n}_{0} \geq \mathrm{n}^{*} \rightarrow \dot{\mathrm{Q}}_{\max } \leq \dot{\mathrm{Q}}\left(\mathrm{n}_{0}\right) \\
\dot{\mathrm{Q}}\left(\mathrm{n}_{0}\right)=\mathrm{k} \ell \cdot \Delta \mathrm{T}_{0 \mathrm{f}}\left\{2 \mathrm{n}_{0}\left[\sqrt{m}+\omega^{\prime} \mathrm{Bi}^{\prime}\right] \mp 2 \omega^{\prime} \mathrm{Bi}^{\prime}\right\}
\end{gathered}
$$

where the sign in upper position is for the "open array" and in lower position for the "closed array" and

$$
\mathrm{n}^{*}=\frac{1}{2} \overline{\mathrm{n}} \cdot\left[1+\sqrt{\frac{\omega^{\prime 2} \mathrm{Bi}^{\prime}}{1+\omega^{\prime 2} \mathrm{Bi}^{\prime}}}\right]
$$

After these remarks, let now examine a suitable approach to perform the optimum design of a fin array, giving the guidelines for the solution of the general case $\left(\omega^{\prime} \neq 0\right.$ and $\left.\omega \neq 0\right)$ and an analytical solution for the particularly meaningful case of fin with insulated tip ( $\omega^{\prime} \neq 0$ and $\omega=0)$.

\section{Fin array optimum design: statement of the problem}

The problem of the optimization of the fin array, contains the number of fins as integer variable. In order to achieve the optimization with respect to the number of fins, the most direct method involves the comparison among optimum fin arrays obtained for different values of the number of fins. In this perspective the optimization method proposed in the paper starts selecting some number of fins, lower than the maximum defined by Eq. (14), to be investigated. For every selected number of fins $n$, the array is optimized imposing the constraint on the heat flow (if the minimization of the weight is considered) or on the weight (if the maximization of the heat flow is considered). The solution of the optimum design is obtained comparing the results relative to different values of the number of fins $n$. In this way the problem is reduced to the optimum design of fin array composed with an assigned number of fins. Among the dimensionless quantities, $\mathrm{n}, \mathrm{Bi}^{\prime}, \mathrm{H} / \mathrm{c}^{\prime}, \omega, \omega^{\prime}$ are preassigned parameters, 
while $\mathrm{Bi}$ and $\rho$ are the design variables. The role of objective function or of equality constraint is played alternatively by the dimensionless weight of the array $\Psi$ and by the array enhancement factor $\Phi$-quantity that differs only for a constant by the dimensionless heat flow-, both divided for the number of fins. The further constraints are given by the convenience criterion and by the more restrictive between the accuracy and the geometrical constraint. Moreover all the design variables must be non negative.

The thermal optimization of the fin array can be expressed in the classical form

$$
\begin{aligned}
& \text { Minimize } \quad[\psi(\rho, \mathrm{Bi})] \\
& \text { subject to } \varphi(\rho, \mathrm{Bi})-\varphi_{0}=0 \\
& \text { or, alternatively } \\
& \text { Maximize } \quad[\varphi(\rho, \mathrm{Bi})] \\
& \text { subject to } \quad \psi(\rho, \mathrm{Bi})-\psi_{0}=0
\end{aligned}
$$

both satisfying the further constraints:

$$
\begin{aligned}
& \rho \geq 0 ; \\
& \mathrm{Bi}>0 ; \\
& \mathrm{Bi} \leq m_{g}(\text { or } m) ; \\
& 1-\hat{\omega}^{2} \cdot \mathrm{Bi} \geq 0
\end{aligned}
$$

The problem can be solved by a non-linear programming method [19-20].

\subsection{Minimization of the weight of the fin array for a given heat flow. General problem}

In the design of fin arrays it is often desirable that the required thermal load be dissipated with the minimum weight. The problem defined by Eqs. (37) and (38) is a non-linear programming problem that can be approached converting inequality into equality constraints, defining a number of auxiliary variables $\beta_{\mathrm{j}}$ equal to the number of inequality constraints and solved by a generalized Lagrange multipliers method. The problem of maximization of the heat flow for a given weight defined by Eqs (37b) and (38) can be solved, defining the function 


$$
\mathrm{L}=2 \rho \mathrm{Bi}^{2}+\lambda_{1}\left[\varphi-\varphi_{0}\right]+\lambda_{2}\left[\rho-\beta_{2}^{2}\right]+\lambda_{3}\left[\mathrm{Bi}-\beta_{3}^{2}\right]+\lambda_{4}\left[m_{g}-\mathrm{Bi}-\beta_{4}^{2}\right]+\lambda_{5}\left[1-\hat{\omega}^{2} \mathrm{Bi}-\beta_{5}^{2}\right]
$$

and solving the system obtained equaling to zero the derivatives of $\mathrm{L}$ with respect to $\rho$ and $\mathrm{Bi}$, to five multipliers $\lambda_{\mathrm{i}}$ and four auxiliary variables $\beta_{\mathrm{i}}$, being 5 the number of constraints, one equality constraint and four inequality constraints:

$$
\left\{\begin{array}{l}
2 \mathrm{Bi}^{2}+\lambda_{1} \frac{2 \mathrm{Bi} \cdot\left(1-\omega^{2} \mathrm{Bi}\right)}{\cosh ^{2}(\rho \sqrt{\mathrm{Bi}}) \cdot[1+\omega \sqrt{\mathrm{Bi}} \cdot \mathrm{th}(\rho \sqrt{\mathrm{Bi}})]^{2}}+\lambda_{2}=0 \\
4 \rho \mathrm{Bi}+\lambda_{1}\left[\frac{\chi}{2 \mathrm{Bi}}+\frac{\rho \cdot\left(1-\omega^{2} \mathrm{Bi}\right)+\omega}{\cosh ^{2}(\rho \sqrt{\mathrm{Bi}}) \cdot[1+\omega \sqrt{\mathrm{Bi}} \cdot \operatorname{th}(\rho \sqrt{\mathrm{Bi}})]^{2}}-2 \omega^{\prime}\right]+\lambda_{3}-\lambda_{4}-\lambda_{5} \hat{\omega}^{2}=0 \\
2 \sqrt{\mathrm{Bi}} \frac{\operatorname{th}(\rho \sqrt{\mathrm{Bi}})+\omega \sqrt{\mathrm{Bi}}}{1+\omega \sqrt{\mathrm{Bi}} \cdot \mathrm{th}(\rho \sqrt{\mathrm{Bi}})}-2 \omega^{\prime} \mathrm{Bi}=\varphi_{0} \\
\rho=\beta_{2}{ }^{2} \\
\mathrm{Bi}=\beta_{3}^{2} \\
\mathrm{Bi}^{2}=m_{g}-\beta_{4}{ }^{2} \\
\hat{\omega}^{2} \mathrm{Bi}=1-\beta_{5}^{2} \\
\lambda_{2} \beta_{2}=0 \\
\lambda_{3} \beta_{3}=0 \\
\lambda_{4} \beta_{4}=0 \\
\lambda_{5} \beta_{5}=0
\end{array}\right.
$$

A complete analysis of the system involves the consideration of 16 different cases, but the only meaningful are those in which $\rho \neq 0, \mathrm{Bi} \neq 0$. So it follows that

$$
\beta_{2}^{2} \neq 0 ; \quad \beta_{3}^{2} \neq 0 \quad \Rightarrow \quad \lambda_{2}=\lambda_{3}=0
$$

Only the cases $\beta_{4}{ }^{2} \geq 0$ and $\beta_{5}{ }^{2} \geq 0$ have to be examined. Four different cases require a discussion.

\section{Case 1}

$$
\begin{aligned}
& \beta_{4}>0 \quad \rightarrow \quad \mathrm{Bi}<m_{g} \quad \rightarrow \quad \lambda_{4}=0 \\
& \beta_{5}>0 \quad \rightarrow \quad \mathrm{Bi}<1 / \hat{\omega}^{2} \quad \rightarrow \quad \lambda_{5}=0
\end{aligned}
$$




$$
\left\{\begin{array}{l}
\lambda_{1}=-\mathrm{Bi} \frac{\cosh ^{2}(\rho \sqrt{\mathrm{Bi}})}{1-\omega^{2} \mathrm{Bi}} \cdot[1+\omega \sqrt{\mathrm{Bi}} \cdot \operatorname{th}(\rho \sqrt{\mathrm{Bi}})]^{2} \\
4 \rho \mathrm{Bi}-\sqrt{\mathrm{Bi}} \cdot \frac{\cosh ^{2}(\rho \sqrt{\mathrm{Bi}})}{1-\omega^{2} \mathrm{Bi}} \cdot(\operatorname{th}(\rho \sqrt{\mathrm{Bi}})+\omega \sqrt{\mathrm{Bi}}) \cdot[1+\omega \sqrt{\mathrm{Bi}} \cdot \operatorname{th}(\rho \sqrt{\mathrm{Bi}})]- \\
-\frac{\mathrm{Bi}}{1-\omega^{2} \mathrm{Bi}}\left[\rho\left(1-\omega^{2} \mathrm{Bi}\right)+\omega\right]+\frac{2 \omega^{\prime} \mathrm{Bi} \cosh ^{2}(\rho \sqrt{\mathrm{Bi}})}{1-\omega^{2} \mathrm{Bi}} \cdot[1+\omega \sqrt{\mathrm{Bi}} \cdot \operatorname{th}(\rho \sqrt{\mathrm{Bi}})]^{2}=0 \\
2 \sqrt{\mathrm{Bi}} \frac{\operatorname{th}(\rho \sqrt{\mathrm{Bi}})+\omega \sqrt{\mathrm{Bi}}}{1+\omega \sqrt{\mathrm{Bi}} \cdot \operatorname{th}(\rho \sqrt{\mathrm{Bi}})}-2 \omega^{\prime} \mathrm{Bi}=\varphi_{0}
\end{array}\right.
$$

After some algebraic passages, from the second equation, the system (41) has a solution obtained by solving the trascendental equation

$$
\left[\operatorname{th}(\rho \sqrt{\mathrm{Bi}})-\frac{3 \rho \sqrt{\mathrm{Bi}}}{\cosh ^{2}(\rho \sqrt{\mathrm{Bi}})}\right] \cdot\left[1-\frac{\omega \sqrt{\mathrm{Bi}} \cdot[\operatorname{th}(\rho \sqrt{\mathrm{Bi}})+\omega \sqrt{\mathrm{Bi}}]}{1+\omega \sqrt{\mathrm{Bi}} \cdot \operatorname{th}(\rho \sqrt{\mathrm{Bi}})}\right]+2 \omega \sqrt{\mathrm{Bi}}-2 \omega^{\prime} \sqrt{\mathrm{Bi}} \cdot[1+\omega \sqrt{\mathrm{Bi}} \operatorname{th}(\rho \sqrt{\mathrm{Bi}})]=0
$$

\section{Cases 2 and 3}

$$
\beta_{4} \geq 0 \quad \rightarrow \mathrm{Bi} \leq m_{g} \quad \rightarrow \lambda_{4}=0 \quad \text { or } \quad \lambda_{4} \neq 0 \beta_{5}=0 \quad \rightarrow \mathrm{Bi}=1 / \hat{\omega}^{2} \quad \rightarrow \quad \lambda_{5} \neq 0
$$

In the case $\hat{\omega}=\omega$ it follows, from the first equation of system (40), that $\mathrm{Bi}=0$, so that no solution is available. If $\hat{\omega}=\omega^{\prime}$, replacing $\mathrm{Bi}=1 / \omega^{\prime 2}$ in the third equation of the system (40), no solution consistent with $\varphi_{0}>0$ exists.

\section{Case 4}

$$
\beta_{4}=0 \quad \rightarrow \quad \mathrm{Bi}=m_{g} \quad \rightarrow \quad \lambda_{4}=0 \quad \text { or } \quad \lambda_{4} \neq 0 \beta_{5} \neq 0 \quad \rightarrow \quad \mathrm{Bi}<1 / \hat{\omega}^{2} \quad \rightarrow \quad \lambda_{5}=0
$$

If $\lambda_{4}=0$ a system of four equations in three unknowns $\mathrm{Bi}, \rho, \lambda_{1}$ and the solution is possible with $\mathrm{Bi}=m_{g}$ only for particular combination of the parameters $\omega, \omega^{\prime}, \mathrm{Bi}^{\prime}, \varphi_{0}$

If $\lambda_{4} \neq 0$ a system of four equations in three unknowns $\mathrm{Bi}, \rho, \lambda_{1}$ and $\lambda_{4}$, and the solution is a boundary one $\mathrm{Bi}=m_{g}$ 


\section{Fin array optimum design. Case of the fin with adiabatic $\operatorname{tip}(\omega=0)$}

The proposed modelling and optimization technique is general and the solution of the optimum design problem corresponds to the solution of a system of non-linear equations as described in the previous case. A suitably simple case, meaningful in a lot of practical applications, including the fuel cell stacks, is the fin array with thermally insulated tip $\left(\mathrm{h}^{*}=0\right.$ and $\omega=0$ ), for which the problem of the optimum design of the fin array with a given number of fins can be solved analytically. Resorting to the generalized Lagrange multipliers method, the solving equation (42), becomes

$$
\left[\operatorname{th}(\rho \sqrt{\mathrm{Bi}})-\frac{3 \rho \sqrt{\mathrm{Bi}}}{\cosh ^{2}(\rho \sqrt{\mathrm{Bi}})}\right]-2 \omega^{\prime} \sqrt{\mathrm{Bi}}=0
$$

Eq. (43) have to be joined with the constraints represented by Eqs. (18), (19) and (21b), and by Eqs. (7) or (13) if the constraint is represented by assigning the weight or the heat flow, respectively. It is important to note that the equation reported in [5] to solve the analogous problem, applying the nomenclature of this paper, is coincident with Eq. (43). For the aim of simplifying the analysis the following auxiliary variables can be introduced

$$
\left\{\begin{array}{l}
u=\rho \sqrt{B i} \\
v=\omega^{\prime} \sqrt{B i}
\end{array}\right.
$$

So that the two dimensionless quantities, similar to those introduced with Eqs (7) and (13) can be defined

$$
\begin{aligned}
& Y=\omega^{\prime 3} \psi=2 u \cdot v^{3} \\
& Z=\omega^{\prime} \cdot \varphi=2 v \cdot[\text { thu }-v]
\end{aligned}
$$

By means of the variables introduced in Eq. (44) the solving equation of the optimum design problem, expressed by Eq. (43) for the fin array with a given number of fins $n$ becomes simply:

$$
\mathrm{v}=\left(\mathrm{thu}-3 \mathrm{u} / \cosh ^{2} \mathrm{u}\right) / 2
$$

For what concerns the constraints, they become upper limitations on the auxiliary variable $\mathrm{v}$

$$
\mathrm{v} \leq 1 \quad \text { fin array thermal convenience criterion }
$$




$$
\begin{aligned}
& \mathrm{v} \leq \mathrm{v}_{\mathrm{m}} \text { accuracy criterion constraint } \\
& \mathrm{v} \leq \mathrm{v}_{\mathrm{g}} \quad \text { geometrical constraint }
\end{aligned}
$$

while according to the definition of the weight $\mathrm{W}_{0}$ or of the heat flow $\dot{\mathrm{Q}}_{0}$, for a given number of fins, according to the selected optimum design problem, a further constraint is the one corresponding to the definition of weight or heat flow:

$$
\begin{aligned}
& \Psi_{0}=\frac{\mathrm{W}_{0}}{\gamma \ell \ell_{\mathrm{ch}}^{2}} \rightarrow \psi_{0}=\frac{\Psi_{0}}{\mathrm{n}} \rightarrow \mathrm{Y}_{0}=\omega^{\prime 3} \psi_{0} \\
& \Phi_{0}=\frac{\dot{\mathrm{Q}}_{0}-\mathrm{h}^{\prime} \ell \mathrm{H} \cdot \Delta \mathrm{T}_{0 \mathrm{f}}}{\mathrm{k} \ell \cdot \Delta \mathrm{T}_{0 \mathrm{f}}} \rightarrow \varphi_{0}=\frac{\Phi_{0}}{\mathrm{n}} \rightarrow \mathrm{Z}_{0}=\omega^{\prime} \varphi_{0}
\end{aligned}
$$

In conclusion, from the system between Eq. (46) and Eq. (45a) with $Y=Y_{0}$, or Eq. (45b) with $\mathrm{Z}=\mathrm{Z}_{0}$, a couple $\mathrm{u}^{*}, \mathrm{v}^{*}$ can be obtained. This couple defines an optimum point if, and only if, the inequality constraint more restrictive of the (47) is satisfied. If $\mathrm{v}^{*}$ does not satisfy the aforesaid constraint, its value is assumed equal to that identified by the more restrictive of the conditions (47), e.g. $\mathrm{v}^{*}=\mathrm{v}_{\mathrm{g}}$. Then, imposing $\mathrm{Y}_{0}$ or $\mathrm{Z}_{0}$, as required by the selected optimum design problem, the value $\mathrm{u}^{*}\left(\mathrm{v}_{\mathrm{g}}\right)$ is obtained as solution of one of the two Eqs. (45). For the assigned number of fins $\mathrm{n}$, the couple $\left(\mathrm{u}^{*}, \mathrm{v}^{*}\right)$, if it exists, provides the minimum weight of the fin array as

$$
\mathrm{W}=\gamma \ell \ell_{\mathrm{ch}} \frac{\mathrm{nY} \mathrm{opt}}{\omega^{13}}
$$

and the corresponding heat flow

$$
\dot{\mathrm{Q}}=\mathrm{k} \ell \cdot \Delta \mathrm{T}_{0 \mathrm{f}} \cdot\left(\frac{\mathrm{nZ}}{\omega_{\mathrm{opt}}}+2 \omega^{\prime} \mathrm{Bi}^{\prime} \frac{\mathrm{H}}{\mathrm{c}^{\prime}}\right)
$$

To better explain the procedure and to understand the difference between the problems of the minimization of the weight and that of the maximization of the heat flow, a separate analysis of the two cases is necessary.

\subsection{Fin array of minimum weight at a given heat flow}

The existence of a solution for this particular problem is strictly dependent on the value of the heat flow that must be dissipated by the fin array. The maximum heat flow, $\dot{\mathrm{Q}}_{\max }$, exchanged by the fin array with the assigned minimum interfin space, $c^{\prime}$, can be calculated according to 
Eqs. (27) and (28). The optimization problem of minimum weight array has a solution only if the assigned heat flow is lower than $\dot{\mathrm{Q}}_{\max }$. Considering the limitation on the heat flow, it is possible to find the range of the number of fins within that the comparison among optimum fin arrays have to be carried out. In particular, it can be shown that the number of fins $n$ is an integer number contained, according to the assigned heat flow, in the following range:

$$
\left[\mathrm{n}_{-}, \mathrm{n}_{+}\right]=\frac{\overline{\mathrm{n}}}{2} \cdot \frac{1+\frac{\omega^{\prime} \Phi_{0}}{\overline{\mathrm{n}}}+2 \omega^{\prime 2} \mathrm{Bi}^{\prime} \pm \sqrt{1-\left[\frac{2 \omega^{\prime} \Phi_{0}}{\overline{\mathrm{n}}}+\frac{1}{\mathrm{Bi}}\left(\frac{\Phi_{0}}{\overline{\mathrm{n}}}\right)^{2}\right]}}{1+\omega^{\prime 2} \mathrm{Bi}^{\prime}}
$$

where the upper value $n_{+}$is always lower than $\bar{n}$.

Basing on the previous assumptions, to solve the optimum design problem of the longitudinal rectangular fin array with adiabatic tip, the procedure for the search of the minimum weight for a given heat flow is the following (Figure 4):

1) if the assigned thermal flow $\dot{\mathrm{Q}}_{0}$ is lower than $\dot{\mathrm{Q}}_{\max }$ given by Eqs. (27) and (28), the array heat transfer enhancement factor $\Phi_{0}$ can be calculated with Eq. (10); by means of Eq. (52) the range of analysis is defined and, as first calculation value for the number of fins, the integer part of $n_{+}$is assumed;

2) for the given $n$, the heat transfer enhancement factor of the single fin $\varphi_{0}$ and the corresponding $Z_{0}$ are calculated with Eq. (49), then solving the system of Eqs. (45b) and (46) the couple $\mathrm{u}_{0}, \mathrm{v}_{0}$ is determined;

3) the value $v_{0} \leq 1$ is compared with the values $v_{m}$ and $v_{g}$ imposed by the one-dimensional criterion (47b) and by the geometrical constraint (47c), the minimum between the compared values is assumed as solution $\mathrm{v}^{*}$;

4) if $\mathrm{v}^{*}=\mathrm{v}_{0}$ then $\mathrm{u}^{*}=\mathrm{u}_{0}$, otherwise, if $\mathrm{v}^{*}=\mathrm{v}_{\mathrm{m}}$ or $\mathrm{v}^{*}=\mathrm{v}_{\mathrm{g}}$, then $\mathrm{u}^{*}$ can be obtained as solution of Eq. (45b) with $\mathrm{v}=\mathrm{v}_{\mathrm{m}}$ or $\mathrm{v}=\mathrm{v}_{\mathrm{g}}$ and $\mathrm{Z}=\mathrm{Z}_{0}$;

5) from the couple $\mathrm{u}^{*}, \mathrm{v}^{*}$ it is possible to determine by Eq. (45a) the corresponding $Y$ and then, by means of Eq. (50), the correspondent weight of the array W;

6) a value of $\mathrm{n}$ lower than the previous one is assumed and the steps 2)-6) are repeated;

7) the weights obtained for different values of the fin number are compared; the fin number for which the absolute minimum weight is obtained, furnishes the couple $u_{\text {opt }}, v_{\text {opt }}$ that is the solution of the optimum design problem. 
From the optimized couple $\mathrm{u}_{\mathrm{opt}}, \mathrm{v}_{\mathrm{opt}}$, the corresponding Bi and $\rho$ and consequently the fin thickness $b$, the fin length $\mathrm{L}$ and the interfin space $\mathrm{c}$ are deduced.

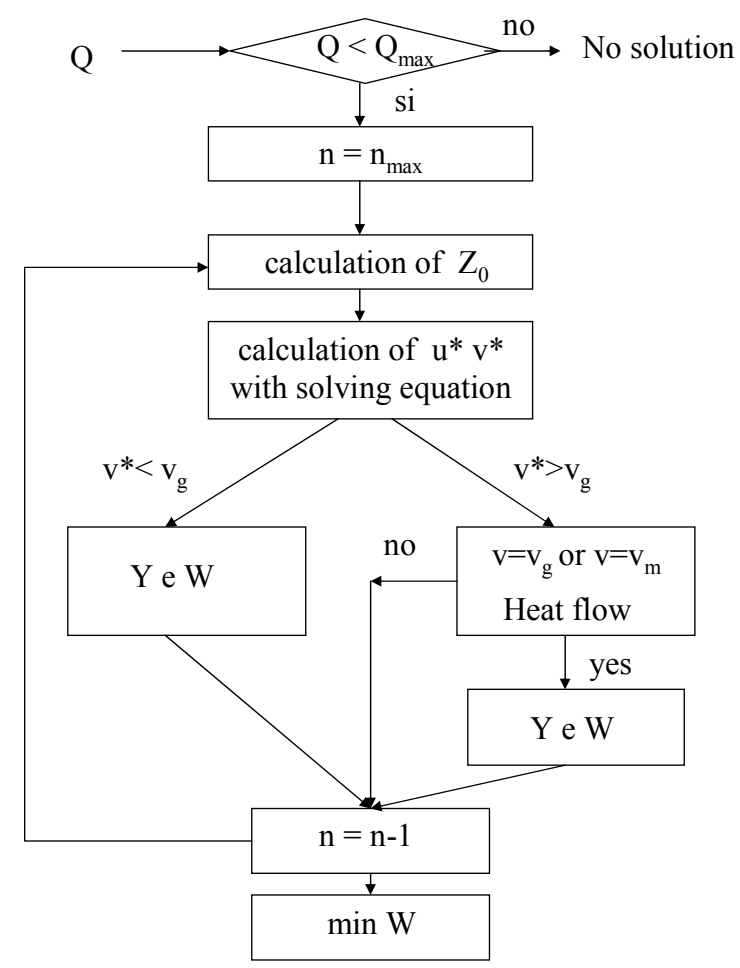

Figure 4. Procedure for the minimization of the weight at given heat flow

\subsection{Fin array with maximum heat flow for a given weight}

Differently with respect to the case of minimum weight examined in the previous paragraph, the existence of the solution is assured for each assigned pesitive value of the weight. The optimization procedure is as follows (Figure 5):

1) From the assigned weight $W_{0}$, the dimensionless weight $\Psi_{0}$ of the fin array is calculated, and the fin number $\mathrm{n}_{\max }$ given by Eq. (14b) is assumed;

2 ) the dimensionless weight of the single fin $\psi$ and the corresponding $Y_{0}$ are calculated, then by solving the system of Eq. (46) and Eq. (45a), with $Y=Y_{0}$, the couple $\mathrm{u}_{0}, \mathrm{v}_{0}$ is determined; 3 ) the value $v_{0} \leq 1$ is compared with the value $v_{m}$ imposed by the 1-D constraint (47b) and $v_{g}$ imposed by the geometrical constraint $(47 \mathrm{c})$, then as solution $\mathrm{v}^{*}$, the minimum among the compared values is assumed;

4) if $\mathrm{v}^{*}=\mathrm{v}_{0}$ then $\mathrm{u}^{*}=\mathrm{u}_{0}$, otherwise, if $\mathrm{v}^{*}=\mathrm{v}_{\mathrm{g}}$, or $\mathrm{v}^{*}=\mathrm{v}_{\mathrm{m}}$, then $\mathrm{v}^{*}$ is inserted inside Eq. (47a) with $\mathrm{Y}=\mathrm{Y}_{0}$ and $\mathrm{u}^{*}$ can be obtained as solution; 
5) from the couple $\mathrm{u}^{*}, \mathrm{v}^{*}$ it is possible to calculate by Eq. (47b) the corresponding $\mathrm{Z}$ and by Eq. (51) the heat flow $\dot{Q}$ of the array;

6) a value of $\mathrm{n}$ lower than the previous one is assumed and the steps 2)-6) are repeated;

7) the heat flows obtained for different values of the fin number are compared; the fin number for which the absolute maximum heat flow is obtained, furnishes the couple $\mathrm{u}_{\mathrm{opt}}, \mathrm{v}_{\mathrm{opt}}$ that is the solution of the optimum design problem.

From the optimized couple $\mathrm{u}_{\mathrm{opt}}, \mathrm{v}_{\mathrm{opt}}$, the correspondent Bi and $\rho$ and consequently the fin thickness $b$, the fin length $L$ and the interfin space $c$, yielding the maximum heat transfer capability are deduced.

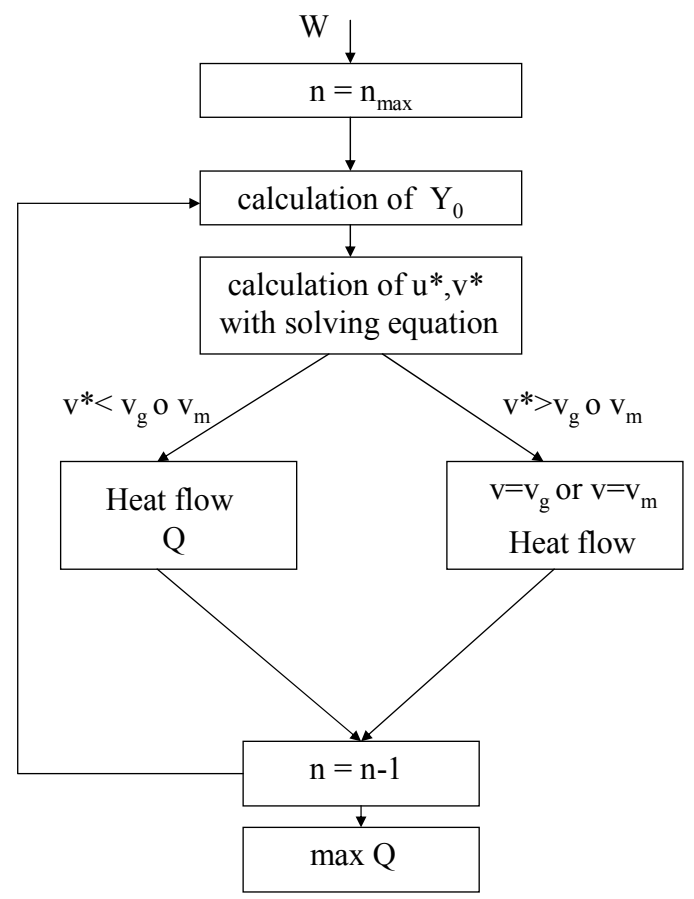

Figure 5. Procedure for the maximization of the heat flow at a given weight

\section{Examples of application of the proposed procedure and comparison with different methods}

In this section a series of examples of the application of the optimum design procedure previously exposed are discussed and analyzed. They concern the fin array with adiabatic tip. All the tables ad figures provide dimensional results referred to a reference test-case, but the same results could be available in dimensionless form. Before furnishing results obtained 
from the present analysis, it is required to validate the method with reference to some existing data. In particular the first application is carried out with reference to the data of a test case extracted from [7] with the aim of validating the method in comparison with one of those proposed in the literature. The problem is to minimize the weight of a "cold-plate", i.e. an array of rectangular fins for a fixed base area, with the following characteristics, for a required heat flow:

$\mathrm{H}=196 \mathrm{~mm}$

$\ell=150 \mathrm{~mm}$

$\mathrm{h}=\mathrm{h}^{\prime}=80 \mathrm{~W} / \mathrm{m}^{2} \mathrm{~K}$

$\mathrm{k}=100 \mathrm{~W} / \mathrm{m} \mathrm{K}$

$\Delta \mathrm{T}_{0 \mathrm{f}}=\mathrm{T}_{0}-\mathrm{T}_{\mathrm{f}}=50{ }^{\circ} \mathrm{C}$

$\gamma=2700 \mathrm{~kg} / \mathrm{m}^{3}$

$\dot{\mathrm{Q}}=470 \mathrm{~W}$

Table 1 provides the results obtained for the cases of "open" and "closed" array with the proposed solution method, for the test case with $\mathrm{c}^{\prime}=15 \mathrm{~mm}$ and assuming as accuracy criterion $\mathrm{Bi} \leq m=0.04$, more restrictive than the convenience one $(\mathrm{Bi} \leq 1)$. For this particular value the condition of Eq. (34) is satisfied with $n \geq 2>n_{0}$ both for open and closed array. Moreover, for both the arrays it is $\mathrm{n}^{*}>\mathrm{n}_{0}$, therefore the solution of the minimum weight problem is possible if the assigned heat flow is lower than the maximum defined by Eqs. (35a); really it is:

$$
\begin{array}{lll}
\text { closed array } & \mathrm{n} \leq \mathrm{n}_{\max }=12 & \dot{\mathrm{Q}}<\dot{\mathrm{Q}}(\mathrm{n} *)=766.41 \mathrm{~W} \\
\text { open array } & \mathrm{n} \leq \mathrm{n}_{\max }=14 & \dot{\mathrm{Q}}<\dot{\mathrm{Q}}(\mathrm{n} *)=873.95 \mathrm{~W}
\end{array}
$$

It this case, the geometrical constraint prevails on the accuracy criterion, so that only the first one has effect on the optimization process. Among the various results, Table 1 provides also, for each examined case, the value of the "fin effectiveness" [1] of the single fin of the array, also mentioned as "fin removal number" [14]. This quantity is defined as the ratio of the heat transferred into the base of the fin to the heat transferred through the same primary surface area if the fins were not present, and it is given by

$$
\varepsilon_{\mathrm{sf}}=\frac{\dot{\mathrm{Q}}_{\mathrm{F}}}{\mathrm{h}^{\prime} \ell \mathrm{b}\left(\mathrm{T}_{0}-\mathrm{T}_{\mathrm{f}}\right)}=\frac{\chi}{2 \omega^{\prime} \mathrm{Bi}}
$$


To have a comparison, the results obtained in [7] by means of the computer code are sensibly different because the optimization result obtained in [7] was:

$$
\mathrm{n}=12 \quad \mathrm{~b}=1.21 \mathrm{~mm} \quad \mathrm{~L}=40 \mathrm{~mm} \quad \mathrm{~W}=234.8 \mathrm{~g}
$$

As can be verified from the Table 2, the minimum weight is obtained for the maximum number of fins for which the given given heat dissipation capability can be obtained:

$$
\begin{array}{lllll}
\text { for "open" array } & \mathrm{n}=13 & \mathrm{~b}=1.06 \mathrm{~mm} & \mathrm{~L}=37.5 \mathrm{~mm} & \mathrm{~W}=210.1 \mathrm{~g} \\
\text { for "closed" array } & \mathrm{n}=11 & \mathrm{~b}=1.45 \mathrm{~mm} & \mathrm{~L}=46.0 \mathrm{~mm} & \mathrm{~W}=298.0 \mathrm{~g}
\end{array}
$$

Table 2. Results of the optimization for the test case with $\dot{\mathbf{Q}}=470 \mathrm{~W}$ for different number of fins ( $\left.\mathrm{c}^{\prime}=\mathbf{1 5} \mathbf{~ m m}\right)$

\begin{tabular}{|c||c|c|c|c|c||c|c|c|c|c|}
\multicolumn{19}{|c|}{ Open array } & \multicolumn{10}{c|}{ Closed array } \\
\hline $\mathbf{n}$ & $\mathbf{b}[\mathbf{m m}]$ & $\mathbf{L}[\mathbf{m m}]$ & $\mathbf{c}[\mathbf{m m}]$ & $\mathbf{W}[\mathbf{g}]$ & $\boldsymbol{\varepsilon}_{\mathbf{s f}}$ & $\mathbf{b}[\mathbf{m m}]$ & $\mathbf{L}[\mathbf{m m}]$ & $\mathbf{c}[\mathbf{m m}]$ & $\mathbf{W}[\mathbf{g}]$ & $\boldsymbol{\varepsilon}_{\text {sf }}$ \\
\hline \hline 13 & 1.06 & 37.50 & 15.18 & 210.1 & 41.46 & & & & & \\
\hline 12 & 1.25 & 40.77 & 16.45 & 248.0 & 38.12 & & & & & \\
\hline 11 & 1.49 & 44.67 & 17.96 & 297.3 & 34.73 & 1.45 & 45.98 & 15 & 297.9 & 35.69 \\
\hline 10 & 1.81 & 49.37 & 19.76 & 362.8 & 31.37 & 1.81 & 49.37 & 16.17 & 362.8 & 31.37 \\
\hline 9 & 2.25 & 55.19 & 21.96 & 452.8 & 27.99 & 2.25 & 55.19 & 17.57 & 452.8 & 27.99 \\
\hline
\end{tabular}

Moreover, it may be noted a significant difference between the absolute optimum of the "open" array and that of the "closed" array (about $88 \mathrm{~g}$ ) and the sensible decrease of the weight (more than the 10\%) respect to the optimization result proposed in [7] is also remarkable. Then it can be observed how in case of "closed" array, the array is optimized on the boundary, i.e. at the limit of the geometrical criterion, so that the interfin space is equal to the minimum permissible value $c^{\prime}=15 \mathrm{~mm}$. Moreover, it can be also verified that, in both the cases, the resulting number of fins is equal to the integer part of the upper limit $n_{+}$of the range defined by Eq. (52).

\subsection{Influence of the variation of the thermal heat flow}

It is of primary interest to examine the influence of the heat flow increase on the optimization result. So Table 3 provides the results obtained with reference to the same data of the previous example, if the heat flow increases, i.e. when $\dot{Q}=700 \mathrm{~W}$, value always lower than the maximum defined by Eqs (35), both for the "closed" and for the "open" array. Examining the results of Table 3, it may be seen how an increase of the heat flow of about the 
$50 \%$ determines a significant increase of the minimum weight of a factor 7 and 10 (for open and closed array, respectively).

Table 3. Results of the optimization for the test case with $\dot{\mathbf{Q}}=700 \mathrm{~W}$ with different number of fins

$$
\text { ( } \left.c^{\prime}=\mathbf{1 5} \mathbf{~ m m}\right)
$$

\begin{tabular}{|c|c|c|c|c|c|c|c|c|c|c|}
\hline \multicolumn{4}{|c|}{ Open array $(3 \leq \mathrm{n} \leq 12)$} & \multicolumn{7}{|c|}{ Closed array $(3 \leq \mathrm{n} \leq 9)$} \\
\hline $\mathbf{n}$ & $\mathbf{b}[\mathrm{mm}]$ & $\mathrm{L}[\mathrm{mm}]$ & c [mm] & W [g] & $\varepsilon_{\mathrm{sf}}$ & b [mm] & $\mathrm{L}[\mathrm{mm}]$ & c [mm] & W [g] & $\varepsilon_{\mathrm{sf}}$ \\
\hline 11 & 4.18 & 76.34 & 15 & 1422.2 & 20.10 & & & & & \\
\hline 10 & 5.10 & 84.59 & 16.11 & 1747.0 & 18.03 & & & & & \\
\hline 9 & 6.35 & 94.97 & 17.35 & 2196.6 & 15.75 & 5.11 & 226.05 & 15 & 4221.4 & 20.10 \\
\hline 8 & 8.12 & 108.26 & 18.72 & 2847.5 & 13.94 & 7.62 & 116.60 & 15 & 2880.6 & 14.91 \\
\hline 7 & 10.75 & 125.88 & 20.12 & 3836.5 & 11.90 & 10.86 & 124.68 & 15 & 3837.7 & 11.77 \\
\hline 6 & 14.91 & 150.36 & 21.31 & 5449.5 & 9.84 & 14.91 & 150.36 & 15.21 & 5449.5 & 9.85 \\
\hline
\end{tabular}

\subsection{Influence of the minimum interfin spacing variation}

For the examined cold-plate let reduce the minimum permissible interfin spacing $\mathrm{c}^{\prime}$ till to the value of $5 \mathrm{~mm}$, instead of the previous $c^{\prime}=15 \mathrm{~mm}$, maintaining the same heat transfer coefficient by an opportune variation of the fluid flow velocity.

In this case the maximum number of fins given by Eq. (14) is $\mathrm{n}_{\max }=38$ for the "closed" array and $\mathrm{n}_{\max }=40$ for the "open" array, while the values of the limit heat flow given by Eq. (35a) are $\dot{\mathrm{Q}}\left(\mathrm{n}^{*}\right)=1342.85 \mathrm{~W}$ and $\dot{\mathrm{Q}}\left(\mathrm{n}^{*}\right)=1407.00 \mathrm{~W}$, for closed and open array respectively. The results obtained with the procedure developed in the paper are illustrated in Table 4, where in the headers the range of variation for the number of fins determined by Eq. (52) are contained. Increasing the heat flow starting from the value $\dot{Q}=700 \mathrm{~W}$ till to values in the proximity of the maximum defined by Eqs. (35a) and (35b), the results of Table 5 can be obtained. From Table 5 it can be seen that, increasing the heat flow, the solution of the optimum design problem, is obtained with a lower number of fins, while the weight increase in a sensible way. These results are concisely summarized in the Figs. 6 and 7 where the optimum fin number and the corresponding minimum weight are reported as a function of $\mathrm{c}^{\prime}$ for an assigned heat flow. In all the cases analyzed the assumption of a constant value of the heat transfer coefficient is reasonable because all the optimization results corresponds to a value of the interfin spacing equal to about the lower bound value. Moreover, it seems particularly interesting to show the effect of the minimum available interfin spacing $c^{\prime}$ on the value of the 
heat flow $\dot{\mathrm{Q}}(\mathrm{n} *)$ determined by Eq. (35a). Figure 8 and Table 6 provide the trend and the detailed values of the upper bound of the maximum heat flow available for the fin array $\dot{\mathrm{Q}}\left(\mathrm{n}^{*}\right)$ in dependence of the minimum interfin spacing $\mathrm{c}^{\prime}$ respectively.

Table 4. Results of the optimization for a given heat flow $\dot{\mathbf{Q}}=700 \mathrm{~W}$ with different fins ( $\mathrm{c}^{\prime}=\mathbf{5 m m}$ ) Open array $(3 \leq \mathrm{n} \leq 38)$

Closed array $(3 \leq \mathrm{n} \leq 36)$

\begin{tabular}{|c||c|c|c|c|c||c|c|c|c|c|}
\hline $\mathrm{N}$ & $\mathrm{b}[\mathrm{mm}]$ & $\mathrm{L}[\mathrm{mm}]$ & $\mathrm{c}[\mathrm{mm}]$ & $\mathrm{W}[\mathrm{g}]$ & $\varepsilon_{\mathrm{sf}}$ & $\mathrm{b}[\mathrm{mm}]$ & $\mathrm{L}[\mathrm{mm}]$ & $\mathrm{c}[\mathrm{mm}]$ & $\mathrm{W}[\mathrm{g}]$ & $\varepsilon_{\mathrm{sf}}$ \\
\hline \hline 38 & 0.29 & 26.22 & 5 & 116.8 & 87.39 & & & & & \\
\hline 37 & 0.35 & 21.41 & 5.08 & 113.6 & 73.10 & & & & & \\
\hline 36 & 0.37 & 22.02 & 5.21 & 120.1 & 71.09 & 0.31 & 34.57 & 5 & 153.9 & 87.11 \\
\hline 35 & 0.40 & 22.66 & 5.35 & 127.2 & 69.03 & 0.40 & 22.66 & 5.06 & 127.2 & 69.03 \\
\hline 34 & 0.42 & 23.35 & 5.50 & 135.0 & 66.97 & 0.42 & 23.35 & 5.19 & 135.0 & 66.97 \\
\hline 33 & 0.45 & 24.07 & 5.67 & 143.5 & 64.95 & 0.45 & 24.07 & 5.33 & 143.5 & 64.95 \\
\hline
\end{tabular}

Table 5. Results of the fin arrays optimization for different values of the imposed heat flow $\dot{\mathbf{Q}}\left(\mathrm{c}^{\prime}=\mathbf{5} \mathbf{~ m m}\right)$

Open array
\begin{tabular}{|c||c|c|c|c|c|c|c|c|c|c|}
\hline$\dot{\mathrm{Q}}[\mathrm{W}]$ & $\mathrm{n}_{\text {opt }}$ & $\mathrm{b}[\mathrm{mm}]$ & $\mathrm{L}[\mathrm{mm}]$ & $\mathrm{c}[\mathrm{mm}]$ & $\mathrm{W}[\mathrm{gr}]$ & $\mathrm{n}_{\text {opt }}$ & $\mathrm{b}[\mathrm{mm}]$ & $\mathrm{L}[\mathrm{mm}]$ & $\mathrm{c}[\mathrm{mm}]$ & $\mathrm{W}[\mathrm{g}]$ \\
\hline \hline 700 & 37 & 0.35 & 21.41 & 5.08 & 113.6 & 35 & 0.40 & 22.66 & 5.06 & 127.2 \\
\hline 800 & 37 & 0.43 & 29.79 & 5 & 193.0 & 34 & 0.58 & 27.48 & 5.04 & 218.9 \\
\hline 900 & 35 & 0.72 & 30.71 & 5.02 & 313.1 & 33 & 0.79 & 33.65 & 5 & 354.4 \\
\hline 1000 & 34 & 0.91 & 38.75 & 5 & 386.5 & 32 & 0.97 & 46.01 & 5 & 577.6 \\
\hline 1100 & 32 & 1.28 & 46.25 & 5 & 768.1 & 30 & 1.37 & 55.82 & 5 & 927.0 \\
\hline 1200 & 30 & 1.70 & 59.21 & 5 & 1222.9 & 27 & 2.07 & 68.59 & 5 & 1555.7 \\
\hline 1300 & 27 & 2.44 & 78.68 & 5 & 2103.1 & 23 & 3.30 & 103.35 & 5 & 3181.1 \\
\hline
\end{tabular}

Table 6. Comparison between the maximum available heat flows as a function of the minimum permissible interfin space $\left(\omega^{\prime}=\mathbf{1}\right)$

\begin{tabular}{|c|c|c|}
\hline$c^{\prime}[\mathrm{mm}]$ & $\dot{\mathrm{Q}}\left(\mathrm{n}^{*}\right)[\mathrm{W}]$ closed array & $\dot{\mathrm{Q}}\left(\mathrm{n}^{*}\right)[\mathrm{W}]$ open array \\
\hline \hline 1 & 2984.69 & 3014.09 \\
\hline 2 & 2117.90 & 2159.15 \\
\hline 3 & 1732.13 & 1782.32 \\
\hline 5 & 1342.85 & 1407.00 \\
\hline 8 & 1059.81 & 1140.00 \\
\hline 10 & 945.84 & 1034.90 \\
\hline 12 & 861.05 & 958.02 \\
\hline 15 & 766.41 & 873.95 \\
\hline 18 & 695.78 & 812.72 \\
\hline 20 & 657.48 & 780.18 \\
\hline
\end{tabular}




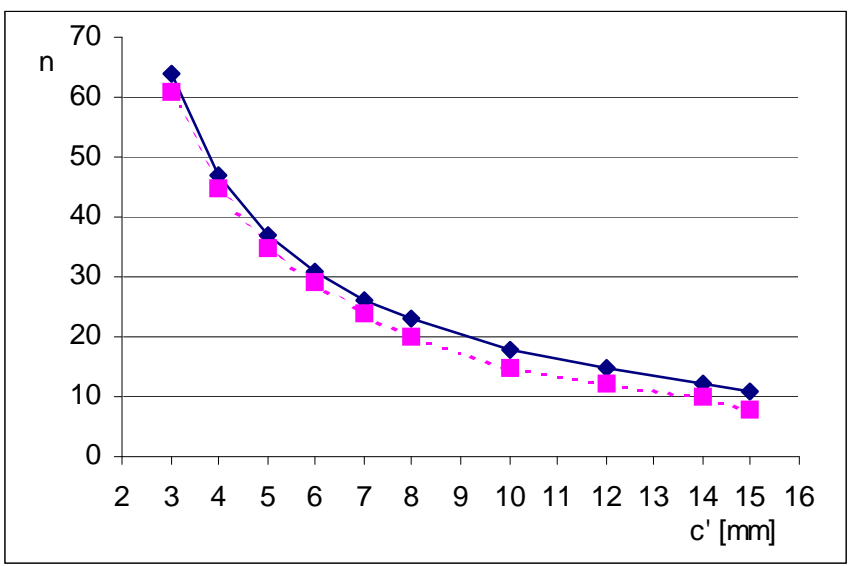

Figure 6. Optimum number of fins as a function of the minimum interfin space. Difference between "open” ( $\bullet)$ and "closed" ( $\mathbf{\square})$ array $(\dot{\mathrm{Q}}=\mathbf{7 0 0} \mathbf{W})$

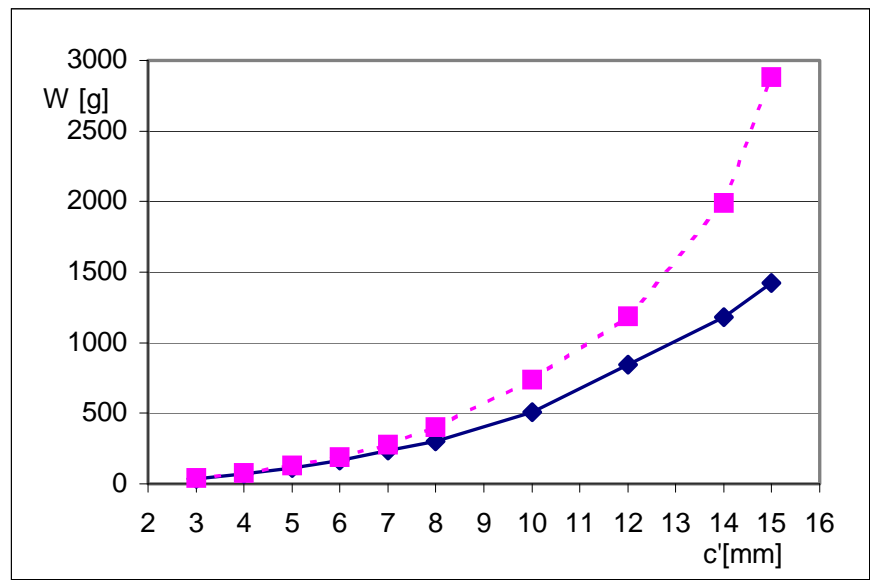

Figure 7. Minimum weigth of the fin array as a function of the minimum interfin space. Difference between “open” ( $\bullet$ ) and “closed” ( $(\mathbf{)}) \operatorname{array}(\dot{\mathrm{Q}}=\mathbf{7 0 0} \mathbf{W})$

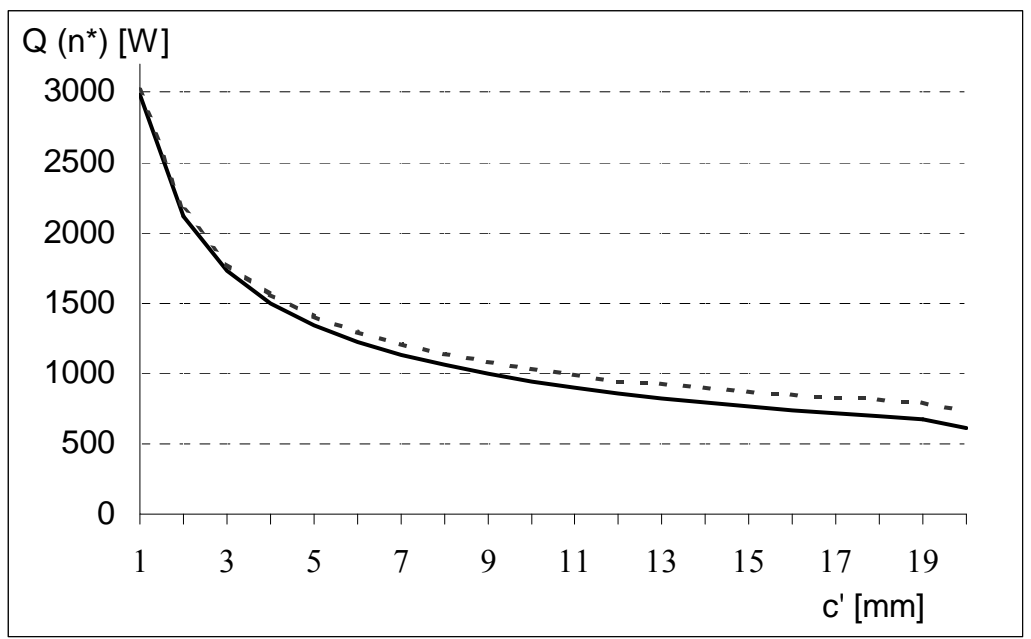

Figure 8. Comparison between the maximum available heat flows for the two cases of open (dotted line) and closed (continuous line) array as a function of the minimum interfin spacing $\left(\omega^{\prime}=\mathbf{1}\right)$ 


\subsection{Influence of the reduction of the heat transfer coefficient on the bottom base}

As final application, it is interesting to show the effect on the result of the optimum design determined by a reduction of the heat transfer coefficient on the primary surface, i.e. of the dimensionless parameter $\omega^{\prime}$.

With reference to the same general data used to obtain the results of the Table 5, if instead of $\omega^{\prime}=1$, the value $\omega^{\prime}=0.6$, deduced from the experimental data of [21], is considered, all the aforementioned consideration about the constraints are still valid and the results of Table 7 can be obtained. In this case the solution of the optimum design problem is possible only for heat flow lower than $\dot{\mathrm{Q}}(\mathrm{n} *)=1317.91 \mathrm{~W}$ for "closed" array and lower than $\dot{\mathrm{Q}}(\mathrm{n} *)=1383.21$ W for "open" array. Comparing the results of Tables 4 and 6 the effect of the reduction of the heat transfer coefficient on the primary surface in the gap between the fins, is a sensible increase of the weight.

Table 7. Optimized fin arrays for a reduced heat transfer coefficient $\left(\omega^{\prime}=\mathbf{0 . 6}\right)$ on the primary surface for different values of the imposed heat flow $\dot{\mathbf{Q}}\left(\mathrm{c}^{\prime}=\mathbf{5} \mathbf{~ m m}\right)$

\begin{tabular}{|c|c|c|c|c|c||c|c|c|c|c|}
\hline$\dot{\mathrm{Q}}[\mathrm{W}]$ & $\mathrm{n}_{\text {opt }}$ & $\mathrm{b}[\mathrm{mm}]$ & $\mathrm{L}[\mathrm{mm}]$ & $\mathrm{c}[\mathrm{mm}]$ & $\mathrm{W}[\mathrm{g}]$ & $\mathrm{n}_{\text {opt }}$ & $\mathrm{b}[\mathrm{mm}]$ & $\mathrm{L}[\mathrm{mm}]$ & $\mathrm{c}[\mathrm{mm}]$ & $\mathrm{W}[\mathrm{g}]$ \\
\hline 700 & 37 & 0.41 & 22.95 & 5.02 & 141.3 & 35 & 0.46 & 24.43 & 5 & 158.3 \\
\hline 800 & 36 & 0.58 & 27.47 & 5 & 233.7 & 34 & 0.62 & 31.14 & 5 & 264.9 \\
\hline 900 & 35 & 0.74 & 35.24 & 5 & 371.1 & 32 & 0.96 & 35.25 & 5.01 & 438.4 \\
\hline 1000 & 33 & 1.09 & 40.10 & 5 & 584.6 & 31 & 1.16 & 46.90 & 5 & 683.8 \\
\hline 1100 & 31 & 1.48 & 49.06 & 5 & 914.0 & 29 & 1.59 & 59.24 & 5 & 1103.7 \\
\hline 1200 & 29 & 1.93 & 63.96 & 5 & 1450.6 & 26 & 2.35 & 76.42 & 5 & 1888.0 \\
\hline 1300 & 26 & 2.73 & 89.16 & 5 & 2563.9 & 22 & 4.14 & 88.51 & 5 & 4546.5 \\
\hline
\end{tabular}

\subsection{Discussion and comparison with other methods}

The optimum design of arrays of longitudinal fins with constant thickness, considering different mean heat transfer coefficients on the fi $\mathrm{n}$ faces and tip, can be recasted to a nonlinear constrained minimization (maximization) problem, that can be solved by means of an analytical procedure easily implemented on computer for solution directly or by means of a support software with a Non Linear Programming package (like the "mincon" function of Matlab Optimization Toolbox). 
Concerning the comparison with other optimization methods available in the literature, in addition to some quantitative differences with the other methods as discussed in section 6 , the method developed in this paper shows that the use of the removal number for the evaluation of the solution, proposed by some authors in the literature, have to be carefully considered. Really the extension of the concept of the effectiveness or removal number of the single fin $\varepsilon_{\text {sf }}$ defined by Eq. (53)- as “qualification parameter" for the fin arrays is ambiguous.

Considering the results of Tables 2 and 3 it seems that for a given heat flow the solution of the minimum weight optimization problem is the one that corresponds to the higher value of the removal number. But considering the results of Table 4 it is possible to observe how, in both the cases, the optimized solution, obtained for a number of fins of the array of 37 for the "closed" array and 35 for the "open" array, does not correspond to the higher value of the removal number of the single fin. This example definitively clarifies the difference between the approach no. 1 that use the classic results of the single fin optimization based on the application of the results available in the classical literature about the extended surfaces as [3] (summarized in Figure 9) and the approach no. 2 described in the introduction for the thermal optimization of fin arrays and object of the work exposed in the present paper.
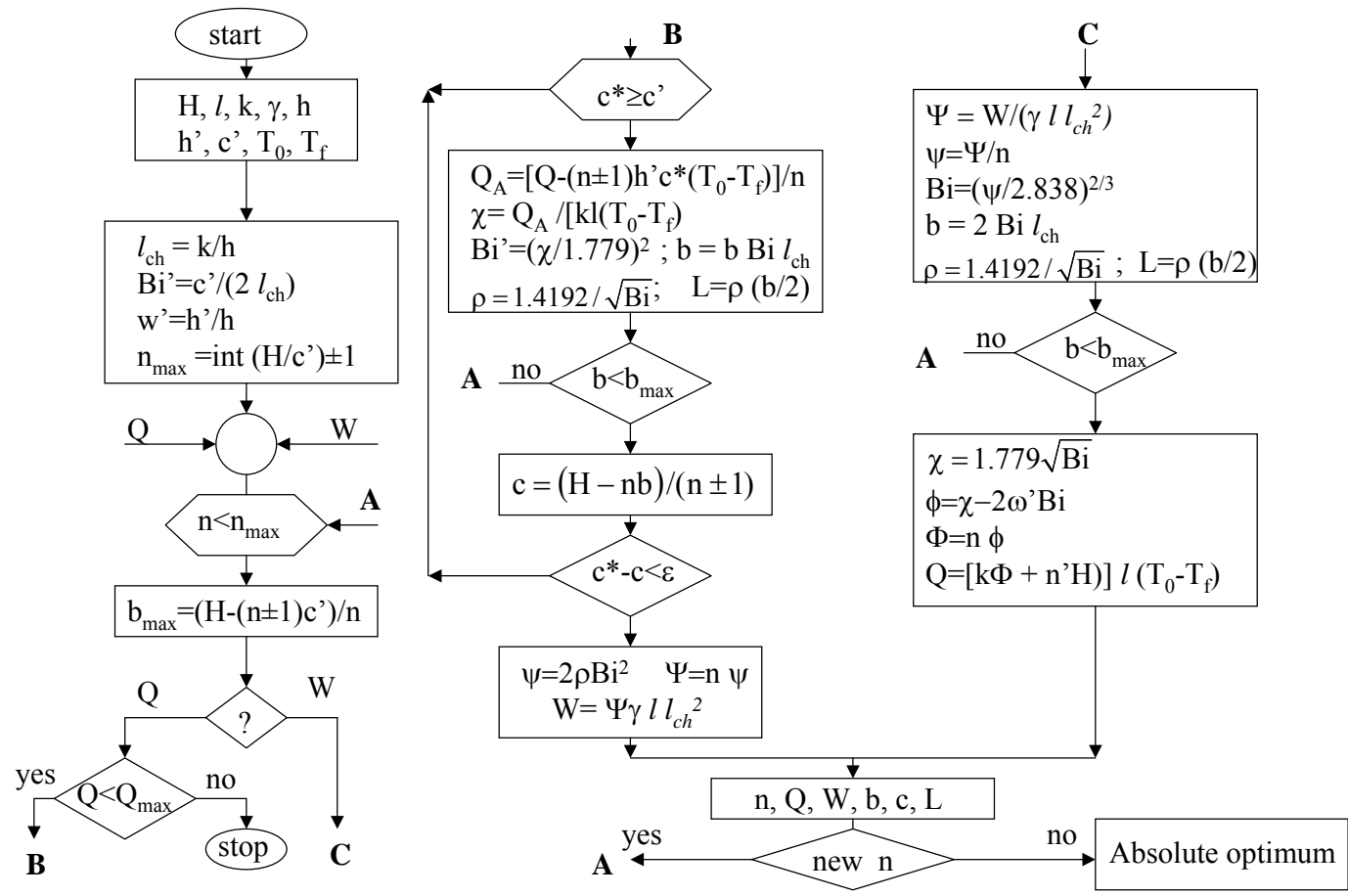

Figure 9. Procedure for the optimization based on the classical results of single fin optimization 


\section{Conclusions}

In this paper a method for the optimization of convective fin arrays composed by longitudinal fins of rectangular profile is proposed. The method developed reduces the multiobective optimization problem of the fin arrays with a "Bonded Objective Function Method" takes into account only thermal analysis, considering the fluid-dynamic variables only in the constraint of maintaining a minimum interfin space between two contiguous fins, so that well defined heat transfer coefficient values could be maintained, neglecting its variation as a function of the interfin spacing.

As optimum design problem the minimization of the weight for a given heat flow (least material optimization) and the maximization of the heat flow for a given weight are considered. A procedure for a general analysis of the problem is given. A detailed analysis has been limited only to fins with insulated tip when an analytical solution of the problem is available. In this case, the two problem examined have often a coincident solution and the possible differences are related to the discrete nature of the variable $n$, the number of fins of the array. Two different configurations has been examined ("open" and "closed" array) and it is shown how the optimal solutions denote meaningful differences.

The problem of the minimum weight optimization for a given heat flow has been considered the more meaningful on the practical point of view, and a series of results related to this case are given. In particular the results obtained in two cases (interfin spacing of the order of 15 $\mathrm{mm}$ and interfin spacing of $5 \mathrm{~mm}$ ) are carefully discussed and analyzed. In both the cases the assumption of considering constant value of the heat transfer coefficients can be considered acceptable assumptions.

First of all some not meaningless differences with respect to other methods are shown, then a critical analysis of the results has been carried out. The results obtained for the optimum design problem are often with the minimum permissible interfin spacing, so, from the mathematical point of view, it means that the optimum design problem has often a solution at the boundary of the domain and it appears to be dominated by the imposed constraints. The optimum number of fins of the array decrease with the increase of the heat flow. Moreover the maximum heat flow at which the optimum design problem has a solution can be analitically determined. For heat flow lower than the 50\% of the maximum defined by Eqs. (35), the optimum fin number is similar to that permitted by the constraint on the minimum interfin spacing, while if the assigned heat flow increases, the optimum fin number is significantly lower than the maximum number permitted by the minimum interfin spacing. It 
is also shown how in the definition of the optimal configuration an important role is played by the heat transfer coefficient on the interfin spacing. A reduction of this value determines a sensible increase of the weight of the fin array.

The trends observed in the analysis of some results discussed in this paper and some heat sinks or fin arrays used shows that manufacturability constraints, when applied to thermal design, will result in heat sinks with reduced thermal performance. For this reason, the procedure developed in the paper seems to be very attractive to be applied to practical heat dissipation problems. The method proposed can be also improved with the introduction of a thermal and fluid dynamic model; in this case it is necessary to introduce a model of the heat transfer coefficient $h$ and of the fritction factor $f$ that will depend on Re number and consequently on the hydraulic diameter of the fin channel, and it will be necessary to complicate the problem with the introduction of a constraint related to the pressure drop in the fin channels.

\section{REFERENCES}

1. Kraus A (1988) Sixty-five years of extended surface technology (1922-1987) Applied Mechanics Review 41: 321-364.

2. Bejan A (1993) Heat Transfer, J. Wiley \& Sons.

3. Kern D, Kraus A (1972) Extended Surface Heat Transfer, Mc Graw-Hill.

4. Kundu, B, Das PK (2009) Performance and optimum design analysis of convective fin arrays attached to flat and curved primary surfaces, Int. Journal of Refrigeration, 32: 430-443.

5. Xu G, Cheng Y, Luo L (2007) Heat-Transfer Characteristics and Design Optimization for a Small-Sized PlateFin Heat Sink Array, ASME Journal of Electronic Packaging 129: 518-521.

6. Bar Cohen A (1979) Fin Thickness for an Optimized Natural Convection Array of Rectangular Fins. ASME Journal of Heat Transfer 101: 564-566.

7. Bar Cohen A, Jelinek M (1985) Optimum Arrays of Longitudinal, Rectangular Fins in Convective Heat Transfer. Heat Transfer Engineering, 6: 68-78.

8. Knight RW, Goodling JS, Hall DJ, (1991) Optimal Thermal Design of Forced Convection Heat SinksAnalytical. ASME Journal of Electronic Packaging. 113: 313-321.

9. Bejan A, Morega AM, (1993) Optimal Arrays of Pin Fins and Plate Fins in Laminar Forced Convection. ASME Journal of Heat Transfer, 115: 75-81.

10. Bar Cohen A, Iyengar M, Kraus AD, (2003), Design of Optimum Plate-Fin Natural Convective Heat Sinks, ASME Journal of Electronic Packaging, 125: 208-216.

11. Gardner KA, (1945) Efficiency of Extended Surfaces. Trans. ASME J. Heat Transfer, 67: 621-631.

12. Casarosa C, Franco A, (2001) On the Optimum Thermal Design of Individual Longitudinal Fins with Rectangular Profile, Heat Transfer Engineering, 22: 51-71.

13. Incropera F, De Witt DP, (1988) Introduction to Heat Transfer, J. Wiley \& Sons: 131. 
14. Razelos P, (1995) The Quest for the Optimum Longitudinal Fin Profile, Heat Transfer Engineering 16: 22. 15. Eckert ERG, Drake R, (1972) Heat and Mass Transfer, Mc Graw Hill.

16. Lau W, Tan CW, (1973) Errors in One-Dimensional Heat Transfer Analysis in Straight and Annular Fins. ASME Journal of Heat Transfer, 95: 549-551.

17. Huang LJ, Shah RK, (1992) Assessment of Calculation Methods for Efficiency of Straight Fins of Rectangular Profile. Int. Journal of Heat and Fluid Flow, 13: 282-293.

18. Aziz A, Lunardini VJ, (1995) Multidimensional Steady Conduction in Convecting, Radiating and Convective-Radiating Fins and Fin Assemblies. Heat Transfer Engineering, 16: 32-64.

19. Wismer DA, Chattergy R, (1978) Introduction to Non-Linear Optimization, North Holland, New York. 20. Rao SS, (1996) Engineering Optimization. Theory and Practice, J. Wiley \& Sons.

21. Stachiewicz G (1969) Effect of Variation of Local Film Coefficient on Fin Performance. ASME Journal of Heat Transfer, 91: 21-26. 